\title{
Article \\ Determining the Anticancer Activity of Sphingosine Kinase Inhibitors Containing Heteroatoms in Their Tail Structure
}

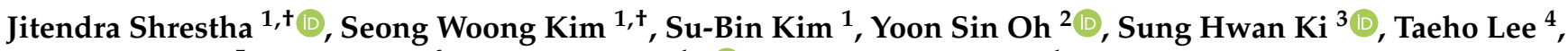 \\ Sang-Bum Kim ${ }^{5}$, Taeuk Park ${ }^{6}$, Dong Jae Baek ${ }^{1, * \mathbb{D}}$ and Eun-Young Park ${ }^{1, *}$ \\ 1 College of Pharmacy, Mokpo National University, Muan-gun 58554, Korea; \\ shresthasimon2011@gmail.com (J.S.); 76pey@naver.com (S.W.K.); rlatnqls0801@naver.com (S.-B.K.) \\ 2 Department of Food and Nutrition, Eulji University, Seongnam 13135, Korea; ysoh@eulji.ac.kr \\ 3 College of Pharmacy, Chosun University, Gwangju 61452, Korea; shki@chosun.ac.kr \\ 4 College of Pharmacy, Research Institute of Pharmaceutical Sciences, Kyungpook National University, \\ Daegu 41566, Korea; tlee@knu.ac.kr \\ 5 New Drug Development Center, Daegu-Gyeongbuk Medical Innovation Foundation, Daegu 41061, Korea; \\ ksb2014@dgmif.re.kr \\ 6 Laboratory Animal Center, Daegu-Gyeongbuk Medical Innovation Foundation, Daegu 41061, Korea; \\ tw3000@dgmif.re.kr \\ * Correspondence: dbaek@mokpo.ac.kr (D.J.B.); parkey@mokpo.ac.kr (E.-Y.P.) \\ + These authors contributed equally to this work.
}

check for updates

Citation: Shrestha, J.; Kim, S.W.; Kim, S.-B.; Oh, Y.S.; Ki, S.H.; Lee, T.; Kim, S.-B.; Park, T.; Baek, D.J.; Park, E.-Y. Determining the Anticancer Activity of Sphingosine Kinase Inhibitors Containing Heteroatoms in Their Tail Structure. Pharmaceutics 2022, 14, 157. https://doi.org/10.3390/ pharmaceutics14010157

Academic Editor: Katarzyna Malarz

Received: 11 November 2021

Accepted: 4 January 2022

Published: 10 January 2022

Publisher's Note: MDPI stays neutral with regard to jurisdictional claims in published maps and institutional affiliations.

Copyright: (c) 2022 by the authors. Licensee MDPI, Basel, Switzerland. This article is an open access article distributed under the terms and conditions of the Creative Commons Attribution (CC BY) license (https:// creativecommons.org/licenses/by/ $4.0 /)$.

\begin{abstract}
Sphingosine kinase (SK) enzyme, a central player of sphingolipid rheostat, catalyzes the phosphorylation of sphingosine to the bioactive lipid mediator sphingosine 1 phosphate (S1P), which regulates cancer cell proliferation, migration, differentiation, and angiogenesis through its extracellular five $\mathrm{G}$ protein-coupled S1P receptors $\left(\mathrm{S}_{1} \mathrm{PR}_{1-5}\right)$. Recently, several research studies on SK inhibitors have taken place in order use them for the development of novel anticancer-targeted therapy. In this study, we designed and synthesized analog derivatives of known SK1 inhibitors, namely RB005 and PF-543, by introducing heteroatoms at their tail structure, as well as investigated their anticancer activities and pharmacokinetic parameters in vitro. Compounds 1-20 of RB005 and PF-543 derivatives containing an aliphatic chain or a tail structure of benzenesulfonyl were synthesized. All compounds of set 1 (1-10) effectively reduced cell viability in both HT29 and HCT116 cells, whereas set 2 derivatives (11-20) showed poor anticancer effect. Compound 10, having the highest cytotoxic effect $\left(48 \mathrm{~h}, \mathrm{HT} 29 \mathrm{IC}_{50}=6.223 \mu \mathrm{M}, \mathrm{HCT} 116 \mathrm{IC}_{50}=8.694 \mu \mathrm{M}\right)$, induced HT29 and HCT116 cell death in a concentration-dependent manner through the mitochondrial apoptotic pathway, which was demonstrated by increased annexin V-FITC level, and increased apoptotic marker cleaved caspase-3 and cleaved PARP. Compound 10 inhibited SK1 by 20\%, and, thus, the S1P level decreased by $42 \%$. Unlike the apoptosis efficacy, the SK1 inhibitory effect and selectivity of the PF-543 derivative were superior to that of the RB005 analog. As a result, compounds with an aliphatic chain tail exhibited stronger apoptotic effects. However, this ability was not proportional to the degree of SK inhibition. Compound 10 increased the protein phosphatase 2A (PP2A) activity (1.73 fold) similar to FTY720 (1.65 fold) and RB005 (1.59 fold), whereas compounds $\mathbf{1 1}$ and $\mathbf{1 3}$ had no effect on PP2A activation. Since the PP2A activity increased in compounds with an aliphatic chain tail, it can be suggested that PP2A activation has an important effect on anticancer and SK inhibitory activities.
\end{abstract}

Keywords: SK inhibitor; colorectal cancer; S1P; derivative; anticancer agent; PP2A

\section{Introduction}

Sphingosine kinase (SK), an evolutionarily conserved lipid kinase, transforms sphingosine into an active lipid mediator sphingosine-1-phosphate (S1P) [1]. S1P regulates various biological processes such as cell proliferation, migration, differentiation, and angiogenesis 
through five G protein-coupled S1P receptors (S1PR) binding [2]. SK has two isotypes, i.e., SK1 and 2, and is present in specific cellular locations. Both the isotypes have potential oncogenic characteristics [3,4] upon overexpression and promote cancer cell proliferation, angiogenesis, metastasis, and resistance against radiation and various chemotherapeutic agents [5,6]. For this reason, SK1 and 2 serve as novel targets for the development of anticancer agents. Various SK1, SK2, and S1PR inhibitors have been developed and tested in several preclinical tumor models.

FTY720 (Gilenya, Novartis), a modulator of the S1P receptor, suppresses immunity and has been developed to treat multiple sclerosis (Figure 1). FTY720 also suppresses SK1 and activates PP2A to show a strong anticancer effect against various cancer cells in vitro and in vivo. For this reason, various sphingolipid modulators with FTY720's structure have been developed. However, the synthesis of FTY720 derivatives is challenging because, structurally, its polar head group and hydrophobic tail are directly connected to the aromatic backbone. Considering this difficulty, several research groups have developed various sphingolipid modulators with a tail structure containing heteroatoms. RB005 is an analog of FTY720 and is a compound that selectively inhibits SK1. Previously, we synthesized several FTY720 analogs, of which compound 7 exhibited PP2A-activating properties and anticancer effects against colorectal and prostate cancer cells [7]. A sphingolipid modulator, K145 [8], having the FTY720 structure, was developed at the University of Virginia. K145 is an SK2 inhibitor that is undergoing development to serve as a leukemia treatment substance. SLM6041434 selectively inhibits [9] SK2, and W-061, with a dihydronaphthalene structure, is an S1P agonist [10] (Figure 1). In these analogs, a polar complex head group and the aliphatic tail of FTY720 are connected with a heteroatom. A tail structure connected by a heteroatom makes it easy to introduce various functional groups synthetically. In addition, this structure reduces solubility in water due to its long hydrophobic tail.

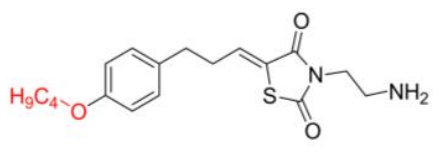

K145 (SK2 inhibitor)

SK1 IC $\mathrm{C}_{50}:>10 \mu \mathrm{M}$ SK2 IC $50: 4.3 \mu \mathrm{M}$

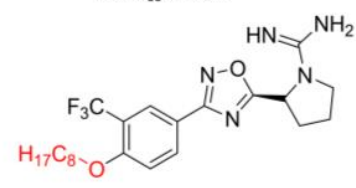

SLM6041434 (SK2 inhibitor)

SK2 Ki: 0.4-1.1 $\mu \mathrm{M}$

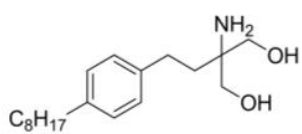

FTY720 (S1P receptor modulator)

SK1, SK2 IC $C_{50}: 5.0-12.5 \mu \mathrm{M}$

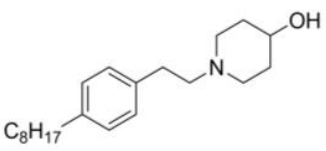

RB-005 (SK1 inhibitor) SK1 IC $50: 3.6 \mu \mathrm{M}$

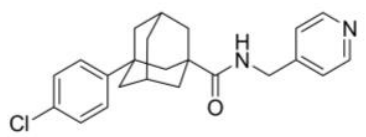

ABC294640 (SK2 inhibitor, Opaganib, Apogee) SK1 IC 50 : $>100 \mu \mathrm{M}$, SK2 IC $50: \sim 60 \mu \mathrm{M}$

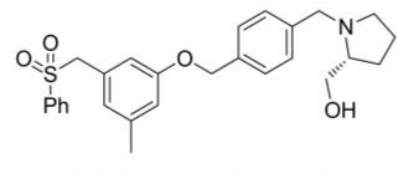

PF-543 (SK1 inhibitor, Pfizer)

SK1 IC $50: 0.0027 \mu \mathrm{M}, \mathrm{SK}_{2} \mathrm{IC}_{50}: 0.36 \mu \mathrm{M}$

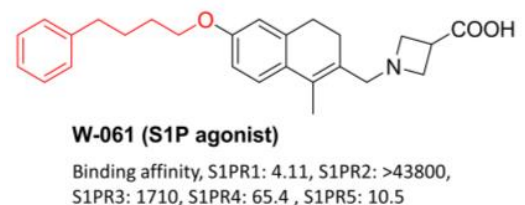

Figure 1. Known sphingolipid regulators containing a heteroatom tail, FTY720 and SK inhibitors.

ABC294640 (Opaganib, Apogee Biotech.) is a substance that exhibits anticancer activity by selectively inhibiting SK2 and is currently undergoing phase 2 clinical trials in various solid cancers (Figure 1) [8]. PF-543, developed by Pfizer, is the strongest SK1 inhibitor [9]. PF-543 demonstrates poor anticancer activity in several cancer cells, despite its strong SK1 inhibitory effect $\left(\mathrm{IC}_{50}=3.4 \mathrm{nM}\right.$, Figure 1) [10]. Although many SK1 inhibitors are being developed, PF-543 still shows the strongest SK1 inhibitory effect, and, for this reason, the development of PF-543 derivatives is required. Pfizer reported the synthesis and SK inhibitory effects of PF-543 derivatives in 2017 [11]. These results revealed that PF-543 still exhibited the highest SK1 inhibitory effect, and the derivatives modified with the 
benzenesulfonyl tail structure of PF-543 showed a lowered SK1 inhibitory effect. These results showed that the benzenesulfonyl tail structure plays an important structural role in the SK1 inhibitory effect. We synthesized a derivative by introducing an aliphatic chain, which was similar to that of FTY720, in the structure of PF-543 and compared SK inhibitory effect and anticancer activity between PF-543 and its derivative [12]. It was revealed that the synthesized PF-543 derivative showed SK1 inhibitory and anticancer effects similar to those of PF-543. However, this synthesis method using Sonogashira coupling is not suitable for synthesizing various derivatives. We designed and synthesized novel RB005 and PF543 analogs by introducing heteroatoms in the tail using a convenient synthesis method. Through this, we tried to confirm the effect of a heteroatom tail on SK inhibitory effect and anticancer activity. In addition, we investigated how the aliphatic tail and benzenesulfonyl tail structures affect anticancer activity using colorectal cancer cells.

\section{Materials and Methods}

\subsection{Chemistry}

\subsubsection{Synthesis in General}

Reagents and solvents used for the reaction were purchased commercially. Silica gel used for column chromatography was grade 60 (230-400 mesh). ${ }^{1} \mathrm{H}-\mathrm{NMR}$ and ${ }^{13} \mathrm{C}$ NMR were measured using JEOL ECZ500R (JEOL Co., Tokyo, Japan) at 500 and $125 \mathrm{MHz}$, respectively, and a deuterated solvent was used. High-resolution mass spectra were measured using an Agilent Technologies G6520A Q-TOF mass spectrometer (Santa Clara, CA, USA) using electrospray ionization (ESI).

\subsubsection{Chemical Synthesis (12-16)}

4-(2-(Trityloxy)ethyl)phenol (12)

To a solution of 4-(2-hydroxyethyl)phenol $(1 \mathrm{~g}, 0.007 \mathrm{~mol})$ and 4-dimethylaminopyridine (DMAP) $(88 \mathrm{mg}, 0.72 \mathrm{mmol})$ in $\mathrm{CH}_{2} \mathrm{Cl}_{2} /$ pyridine $(1 / 2,100 \mathrm{~mL})$ was added trityl chloride $(2 \mathrm{~g}, 0.007 \mathrm{~mol})$ at $\mathrm{rt}$. After the reaction, the mixture was stirred at room temperature for $1 \mathrm{~d}$, and the mixture was extracted with EtOAc. The combined organic phases were washed with brine, dried and concentrated. Flash column chromatography with $n$-hexane:EtOAc $(3: 1(v / v))$ as the eluent gave compound $12(1.49 \mathrm{~g}, 56 \%):{ }^{1} \mathrm{H}$ NMR $\left(500 \mathrm{MHz}, \mathrm{CDCl}_{3}\right) \delta$ 7.41-7.36 (m, 6H), 7.32-7.25 (m, 6H), 7.24-7.20 (m, 3H), $7.05(\mathrm{~d}, J=8.7 \mathrm{~Hz}, 2 \mathrm{H}), 6.75(\mathrm{~d}$, $J=8.7 \mathrm{~Hz}, 2 \mathrm{H}), 3.26(\mathrm{t}, J=7.1 \mathrm{~Hz}, 2 \mathrm{H}), 2.82(\mathrm{t}, J=7.2 \mathrm{~Hz}, 2 \mathrm{H}) ;{ }^{13} \mathrm{C}$ NMR $\left(125 \mathrm{MHz}, \mathrm{CDCl}_{3}\right) \delta$ $185.3,154.1,149.2,143.3,185.3,185.3,257.3,127.4,127.0,115.2,65.3,35.9$; ESI-HRMS (M+H) ${ }^{+}$ $\mathrm{m} / \mathrm{z}$ calcd for $\mathrm{C}_{27} \mathrm{H}_{25} \mathrm{O}_{2} 381.1855$, found 381.1870 .

(4-(Heptyloxy)phenethoxy)methanetriyl)tribenzene (13)

Compound $12(1 \mathrm{~g}, 0.0026 \mathrm{~mol})$ was dissolved in DMF $(100 \mathrm{~mL}), \mathrm{K}_{2} \mathrm{CO}_{3}(1.08 \mathrm{~g}$ $0.0078 \mathrm{~mol})$ and 1-bromoheptane $(0.83 \mathrm{~mL}, 0.0053 \mathrm{~mol})$ were added, and the mixture was stirred at $80^{\circ} \mathrm{C}$ for $12 \mathrm{~h}$. Water was added to stop the reaction, and it was concentrated under reduced pressure after EtOAc extraction and $\mathrm{MgSO}_{4}$ drying. The mixture was separated by column chromatography ( $n$-hexane:EtOAc $=5: 1)$ to give compound $13(0.94 \mathrm{~g}$, 75\%): ${ }^{1} \mathrm{H}$ NMR $\left(500 \mathrm{MHz}, \mathrm{CDCl}_{3}\right)$ 8 7.39-7.34 (m, 6H), 7.27-7.23 (m, 6H), 7.22-7.17 (m, 3H), $7.08(\mathrm{~d}, J=8.6 \mathrm{~Hz}, 2 \mathrm{H}), 6.80(\mathrm{~d}, J=8.7 \mathrm{~Hz}, 2 \mathrm{H}), 3.91(\mathrm{t}, J=6.6 \mathrm{~Hz}, 2 \mathrm{H}), 3.23(\mathrm{t}, J=7.0 \mathrm{~Hz}$, $2 \mathrm{H}), 2.82(\mathrm{t}, J=7.0 \mathrm{~Hz}, 2 \mathrm{H}), 1.43(\mathrm{ddd}, J=12.1,9.2,6.9 \mathrm{~Hz}, 2 \mathrm{H}), 1.38-1.24(\mathrm{~m}, 6 \mathrm{H}), 0.88(\mathrm{t}$, $J=6.9 \mathrm{~Hz}, 3 \mathrm{H}) ;{ }^{13} \mathrm{C}$ NMR $\left(125 \mathrm{MHz}, \mathrm{CDCl}_{3}\right) \delta 157.7,144.4,131.2,130.2,128.8,128.0,127.8$, $126.9,114.4,86.6,68.1,65.3,35.9,31.9,31.6,29.4,29.2,29.0,26.1,22.7,14.2$; ESI-HRMS (M + $\mathrm{H})^{+} \mathrm{m} / z$ calcd for $\mathrm{C}_{34} \mathrm{H}_{39} \mathrm{O}_{2}$ 479.2950, found 479.2915.

\section{4-(Heptyloxy)phenethyl 4-methylbenzenesulfonate (15)}

Compound 13 (500 mg, $1.044 \mathrm{~mol}$ ) was dissolved in $\mathrm{MeOH} / \mathrm{CH}_{2} \mathrm{Cl}_{2}(5 / 1,50 \mathrm{~mL})$, conc. $\mathrm{HCl}(1 \mathrm{~mL})$ was added thereto, and the mixture was stirred at $50{ }^{\circ} \mathrm{C}$ for 5 days. Water was added to stop the reaction, and it was concentrated under reduced pressure after EtOAc extraction and $\mathrm{MgSO}_{4}$ drying. The resulting mixture 14 was dissolved in $\mathrm{CH}_{2} \mathrm{Cl}_{2}$ 
$(50 \mathrm{~mL})$ without purification, and triethylamine $(0.73 \mathrm{~mL}, 0.005 \mathrm{~mol})$ and $p$-toluenesulfonyl chloride $(299 \mathrm{mg}, 1.567 \mathrm{mmol})$ were added thereto and stirred at room temperature for $12 \mathrm{~h}$. The reaction was terminated with water and EtOAc, and the organic layer was dried over $\mathrm{MgSO}_{4}$ and concentrated under reduced pressure. The resulting mixture was separated by column chromatography ( $n$-hexane:EtOAc = 5:1) to give compound $15(171 \mathrm{mg}, 42 \%):{ }^{1} \mathrm{H}$ $\operatorname{NMR}\left(500 \mathrm{MHz}, \mathrm{CDCl}_{3}\right) \delta 7.68(\mathrm{~d}, J=8.3 \mathrm{~Hz}, 2 \mathrm{H}), 7.27(\mathrm{~d}, J=8.6 \mathrm{~Hz}, 2 \mathrm{H}), 7.11(\mathrm{~d}, J=8.7 \mathrm{~Hz}$, $2 \mathrm{H}), 7.00(\mathrm{~d}, J=8.7 \mathrm{~Hz}, 2 \mathrm{H}), 4.15(\mathrm{t}, J=7.1 \mathrm{~Hz}, 2 \mathrm{H}), 3.92(\mathrm{t}, J=6.6 \mathrm{~Hz}, 2 \mathrm{H}), 2.87(\mathrm{t}, J=7.1 \mathrm{~Hz}$, 2H), $2.42(\mathrm{~s}, 3 \mathrm{H}), 1.76(\mathrm{tt}, J=7.0,3.6 \mathrm{~Hz}, 2 \mathrm{H}), 1.44(\mathrm{dt}, J=15.0,7.0 \mathrm{~Hz}, 2 \mathrm{H}), 1.39-1.25(\mathrm{~m}$, $6 \mathrm{H}), 0.89(\mathrm{t}, J=6.7 \mathrm{~Hz}, 3 \mathrm{H})$; ESI-HRMS $(\mathrm{M}+\mathrm{H})^{+} \mathrm{m} / z$ calcd for $\mathrm{C}_{22} \mathrm{H}_{31} \mathrm{O}_{4} \mathrm{~S} 391.1943$, found 391.1992 .

\section{4-(2-((Phenylsulfonyl)oxy)ethyl)phenyl benzenesulfonate (16)}

After 4-(2-hydroxyethyl)phenol ( $1 \mathrm{~g}, 0.0072 \mathrm{~mol})$ was dissolved in 1,2-dichloromethane $(40 \mathrm{~mL})$, triethylamine $(5 \mathrm{~mL}, 0.036 \mathrm{~mol})$ and benzenesulfonyl chloride $(3.8 \mathrm{~g}, 0.022 \mathrm{~mol})$ were added at rt. It was stirred for $12 \mathrm{~h}$. Water and EtOAc were added to the reaction mixture, and the organic layer was dried with $\mathrm{MgSO}_{4}$. The resulting mixture was separated by column chromatography ( $n$-hexane:EtOAc $=10: 1)$ to give compound $16(2.7 \mathrm{~g}, 89 \%):{ }^{1} \mathrm{H}$ NMR (500 MHz, $\left.\mathrm{CDCl}_{3}\right) \delta 7.78(\mathrm{ddt}, J=23.5,8.4,1.3 \mathrm{~Hz}, 4 \mathrm{H}), 7.63(\mathrm{dddd}, J=8.1,7.3,5.1,1.3$ $\mathrm{Hz}, 2 \mathrm{H}), 7.54-7.45(\mathrm{~m}, 4 \mathrm{H}), 7.01(\mathrm{dd}, J=8.4,1.2 \mathrm{~Hz}, 2 \mathrm{H}), 6.84(\mathrm{dd}, J=8.6,1.5 \mathrm{~Hz}, 2 \mathrm{H}), 4.18$ $(\mathrm{td}, J=6.7,1.5 \mathrm{~Hz}, 2 \mathrm{H}), 2.90(\mathrm{t}, J=6.7 \mathrm{~Hz}, 2 \mathrm{H}) ;{ }^{13} \mathrm{C} \mathrm{NMR}\left(125 \mathrm{MHz}, \mathrm{CDCl}_{3}\right) \delta 148.5,135.9$, 135.6, 135.4, 134.4, 133.9, 130.2, 129.3, 128.5, 127.8, 122.6, 70.4, 34.7; ESI-HRMS (M + H $)^{+}$ $m / z$ calcd for $\mathrm{C}_{20} \mathrm{H}_{19} \mathrm{O}_{6} \mathrm{~S}_{2} 419.0623$, found 419.0611 .

\subsubsection{Synthesis of Compounds 1-20}

To a solution of $15(50 \mathrm{mg}, 0.13 \mathrm{mmol})$ or $16(50 \mathrm{mg}, 0.12 \mathrm{mmol})$ in $7 \mathrm{~mL}$ of acetonitrile was added cyclic amine $(0.38 \mathrm{mmol})$. The reaction mixture was stirred at $50{ }^{\circ} \mathrm{C}$ for $12 \mathrm{~h}$ and concentrated. Purification by silica gel chromatography, eluting with $\mathrm{CH}_{2} \mathrm{Cl}_{2} / \mathrm{MeOH}$ (10:1), gave compounds 1-20. Cyclic amine $((R)-(-)$-prolinol (1, 11), piperidine $(\mathbf{2}, \mathbf{1 2}), 4$ hydroxypiperidine $(3,13)$, morpholine $(4,14),(S)-(+)$-prolinol $(5,15), 4$-piperidinemethanol $(6,16), 1$-methylpiperidine $(7,17), 3$-piperidinemethanol $(8,18)$, piperazine $(9,19), 1-(2-$ hydroxyethyl)piperazine $(\mathbf{1 0}, \mathbf{2 0}))$ was used for each reaction.

(R)-(1-(4-(Heptyloxy)phenethyl)pyrrolidin-2-yl)methanol (1): ${ }^{1} \mathrm{H} \mathrm{NMR}\left(500 \mathrm{MHz}, \mathrm{CDCl}_{3}\right)$ $\delta 7.11(\mathrm{~d}, J=8.6 \mathrm{~Hz}, 2 \mathrm{H}), 6.81(\mathrm{~d}, J=8.6 \mathrm{~Hz}, 2 \mathrm{H}), 3.93(\mathrm{dd}, J=13.1,3.0 \mathrm{~Hz}, 1 \mathrm{H}), 3.89(\mathrm{t}$, $J=6.6 \mathrm{~Hz}, 2 \mathrm{H}), 3.83(\mathrm{dd}, J=13.1,6.5 \mathrm{~Hz}, 1 \mathrm{H}), 3.76-3.70(\mathrm{~m}, 1 \mathrm{H}), 3.52-3.41(\mathrm{~m}, 1 \mathrm{H}), 3.39-3.34$ $(\mathrm{m}, 1 \mathrm{H}), 3.20(\mathrm{ddd}, J=14.6,10.7,7.7 \mathrm{~Hz}, 1 \mathrm{H}), 3.06-2.96(\mathrm{~m}, 2 \mathrm{H}), 2.85-2.78(\mathrm{~m}, 1 \mathrm{H}), 2.14-1.93$ $(\mathrm{m}, 4 \mathrm{H}), 1.78-1.69(\mathrm{~m}, 2 \mathrm{H}), 1.42(\mathrm{dt}, J=15.0,6.9 \mathrm{~Hz}, 2 \mathrm{H}), 1.36-1.23(\mathrm{~m}, 6 \mathrm{H}), 0.87(\mathrm{t}, J=6.9 \mathrm{~Hz}$, $3 \mathrm{H}) ;{ }^{13} \mathrm{C}$ NMR $\left(125 \mathrm{MHz}, \mathrm{CDCl}_{3}\right) \delta 158.3,129.8,115.0,68.1,60.9,54.8,31.9,31.5,29.3,29.1$, 26.5, 26.1, 24.1, 22.7, 14.2; ESI-HRMS $(\mathrm{M}+\mathrm{H})^{+} \mathrm{m} / z$ calcd for $\mathrm{C}_{20} \mathrm{H}_{34} \mathrm{NO}_{2} 320.2590$, found 320.2528 .

1-(4-(Heptyloxy)phenethyl)piperidine (2): ${ }^{1} \mathrm{H} \mathrm{NMR}\left(500 \mathrm{MHz}, \mathrm{CDCl}_{3}\right) \delta 7.10(\mathrm{~d}, J=8.6 \mathrm{~Hz}$, $2 \mathrm{H}), 6.79(\mathrm{~d}, J=8.7 \mathrm{~Hz}, 2 \mathrm{H}), 3.88(\mathrm{t}, J=6.6 \mathrm{~Hz}, 2 \mathrm{H}), 3.11-3.04(\mathrm{~m}, 2 \mathrm{H}), 3.01-2.94(\mathrm{~m}, 2 \mathrm{H})$, 2.01-1.90 (m, 2H), $1.73(\mathrm{dq}, J=13.3,6.6 \mathrm{~Hz}, 2 \mathrm{H}), 1.64-1.52(\mathrm{~m}, 2 \mathrm{H}), 1.44-1.37(\mathrm{~m}, 2 \mathrm{H})$, $1.35-1.18(\mathrm{~m}, 8 \mathrm{H}), 0.86(\mathrm{t}, J=6.9 \mathrm{~Hz}, 3 \mathrm{H}) ;{ }^{13} \mathrm{C} \mathrm{NMR}\left(125 \mathrm{MHz}, \mathrm{CDCl}_{3}\right) \delta 158.2,129.8,126.0$, $114.9,68.1,59.5,53.6,31.9,30.0,29.3,29.1,26.1,23.3,22.6,14.1$; ESI-HRMS $(\mathrm{M}+\mathrm{H})^{+} m / z$ calcd for $\mathrm{C}_{20} \mathrm{H}_{34} \mathrm{NO} 304.2640$, found 304.2639.

1-(4-(Heptyloxy)phenethyl)piperidin-4-ol (3): ${ }^{1} \mathrm{H}$ NMR (500 MHz, $\left.\mathrm{CDCl}_{3}\right) \delta 6.99$ (d, $J=8.6 \mathrm{~Hz}, 2 \mathrm{H}), 6.74(\mathrm{~d}, J=8.7 \mathrm{~Hz}, 2 \mathrm{H}), 4.00-3.91(\mathrm{~m}, 1 \mathrm{H}), 3.86(\mathrm{t}, J=6.6 \mathrm{~Hz}, 2 \mathrm{H}), 3.19(\mathrm{t}$, $J=9.1 \mathrm{~Hz}, 2 \mathrm{H}), 2.96-2.87(\mathrm{~m}, 6 \mathrm{H}), 2.14-2.07(\mathrm{~m}, 2 \mathrm{H}), 1.90-1.84(\mathrm{~m}, 2 \mathrm{H}), 1.72(\mathrm{dq}, J=13.3,6.6$ $\mathrm{Hz}, 2 \mathrm{H}), 1.40(\mathrm{dq}, J=9.1,6.8 \mathrm{~Hz}, 2 \mathrm{H}), 1.35-1.22(\mathrm{~m}, 6 \mathrm{H}), 0.86(\mathrm{t}, J=6.9 \mathrm{~Hz}, 3 \mathrm{H}) ;{ }^{13} \mathrm{C} \mathrm{NMR}$ $\left(125 \mathrm{MHz}, \mathrm{CDCl}_{3}\right) \delta 158.2,129.8,129.1,114.8,68.1,58.9,31.9,29.4,29.2,26.2,22.8,21.4,14.2$; ESI-HRMS $(\mathrm{M}+\mathrm{H})^{+} \mathrm{m} / z$ calcd for $\mathrm{C}_{20} \mathrm{H}_{34} \mathrm{NO}_{2} 320.2590$, found 320.2591 . 
4-(4-(Heptyloxy)phenethyl)morpholine (4): ${ }^{1} \mathrm{H}$ NMR $\left(500 \mathrm{MHz}, \mathrm{CDCl}_{3}\right) \delta 7.09$ (d, J=8.6 Hz, $2 \mathrm{H}), 6.81(\mathrm{~d}, J=8.6 \mathrm{~Hz}, 2 \mathrm{H}), 3.91(\mathrm{t}, J=6.6 \mathrm{~Hz}, 2 \mathrm{H}), 3.80-3.72(\mathrm{~m}, 4 \mathrm{H}), 2.76(\mathrm{dd}, J=9.9$, $6.5 \mathrm{~Hz}, 2 \mathrm{H}), 2.64-2.48(\mathrm{~m}, 6 \mathrm{H}), 1.75(\mathrm{dt}, J=14.6,6.6 \mathrm{~Hz}, 2 \mathrm{H}), 1.43(\mathrm{ddd}, J=12.1,9.1,6.9 \mathrm{~Hz}$, 2H), $1.38-1.23(\mathrm{~m}, 6 \mathrm{H}), 0.88(\mathrm{t}, J=6.9 \mathrm{~Hz}, 3 \mathrm{H}) ;{ }^{13} \mathrm{C} \mathrm{NMR}\left(125 \mathrm{MHz}, \mathrm{CDCl}_{3}\right) \delta 157.7,129.6$, 128.0, 114.6, 68.1, 66.9, 61.1, 53.7, 31.9, 29.4, 29.2, 26.1, 22.7, 14.2; ESI-HRMS (M + H $)^{+} m / z$ calcd for $\mathrm{C}_{19} \mathrm{H}_{32} \mathrm{NO}_{2} 306.2433$, found 306.2478.

(S)-(1-(4-(Heptyloxy)phenethyl)pyrrolidin-2-yl)methanol (5): ${ }^{1} \mathrm{H}$ NMR $\left(500 \mathrm{MHz}, \mathrm{CDCl}_{3}\right) \delta$ $7.13(\mathrm{~d}, J=8.6 \mathrm{~Hz}, 2 \mathrm{H}), 6.83(\mathrm{~d}, J=8.6 \mathrm{~Hz}, 2 \mathrm{H}), 3.91(\mathrm{t}, J=6.6 \mathrm{~Hz}, 2 \mathrm{H}), 3.86-3.79(\mathrm{~m}, 1 \mathrm{H})$, 3.47 (ddd, $J=11.1,9.2,5.7 \mathrm{~Hz}, 2 \mathrm{H}), 3.39-3.30(\mathrm{~m}, 1 \mathrm{H}), 3.17-3.02(\mathrm{~m}, 2 \mathrm{H}), 2.87$ (ddd, $J=14.5$, 7.0, 4.2 Hz, 1H), 2.26-2.14 (m, 2H), 2.11-1.99 (m, 4H), 1.75 (dt, $J=14.5,6.6 \mathrm{~Hz}, 2 \mathrm{H}), 1.47-1.38$ $(\mathrm{m}, 2 \mathrm{H}), 1.37-1.17(\mathrm{~m}, 6 \mathrm{H}), 0.88(\mathrm{t}, J=6.7 \mathrm{~Hz}, 3 \mathrm{H}) ;{ }^{13} \mathrm{C} \mathrm{NMR}\left(125 \mathrm{MHz}, \mathrm{CDCl}_{3}\right) \delta 158.5$, 129.8, 127.7, 115.1, 71.4, 68.2, 60.8, 58.7, 54.8, 31.9, 31.0, 29.8, 29.3, 29.1, 26.4, 26.1, 24.4, 22.7, 14.2; ESI-HRMS $(\mathrm{M}+\mathrm{H})^{+} \mathrm{m} / z$ calcd for $\mathrm{C}_{20} \mathrm{H}_{34} \mathrm{NO}_{2} 320.2590$, found 320.2531 .

(1-(4-(Heptyloxy)phenethyl)piperidin-4-yl)methanol (6): ${ }^{1} \mathrm{H}$ NMR (500 MHz, $\left.\mathrm{CDCl}_{3}\right) \delta 7.07$ $(\mathrm{d}, J=8.6 \mathrm{~Hz}, 2 \mathrm{H}), 6.79(\mathrm{~d}, J=8.7 \mathrm{~Hz}, 2 \mathrm{H}), 3.89(\mathrm{t}, J=6.6 \mathrm{~Hz}, 2 \mathrm{H}), 3.70-3.60(\mathrm{~m}, 2 \mathrm{H}), 3.53(\mathrm{~d}$, $J=5.9 \mathrm{~Hz}, 2 \mathrm{H}), 3.13-3.03(\mathrm{~m}, 4 \mathrm{H}), 2.79-2.61(\mathrm{~m}, 2 \mathrm{H}), 2.03-1.86(\mathrm{~m}, 4 \mathrm{H}), 1.74(\mathrm{dt}, J=14.6,6.6$ $\mathrm{Hz}, 3 \mathrm{H}), 1.41(\mathrm{tt}, J=9.3,6.8 \mathrm{~Hz}, 2 \mathrm{H}), 1.37-1.22(\mathrm{~m}, 6 \mathrm{H}), 0.87(\mathrm{t}, J=7.0 \mathrm{~Hz}, 3 \mathrm{H}) ;{ }^{13} \mathrm{C} \mathrm{NMR}$ $\left(125 \mathrm{MHz}, \mathrm{CDCl}_{3}\right) \delta 158.4,129.8,126.0,115.0,68.2,65.0,61.2,48.1,34.2,31.9,29.3,29.1,26.1$, 22.7, 21.4, 14.2; ESI-HRMS $(\mathrm{M}+\mathrm{H})^{+} \mathrm{m} / z$ calcd for $\mathrm{C}_{21} \mathrm{H}_{36} \mathrm{NO}_{2} 334.2746$, found 334.2799 .

1-(4-(Heptyloxy)phenethyl)-4-methylpiperidine (7): ${ }^{1} \mathrm{H} \mathrm{NMR}\left(500 \mathrm{MHz}, \mathrm{CDCl}_{3}\right) \delta 7.09$ (d, $J=8.6 \mathrm{~Hz}, 2 \mathrm{H}), 6.78(\mathrm{~d}, J=8.6 \mathrm{~Hz}, 2 \mathrm{H}), 3.87(\mathrm{t}, J=6.6 \mathrm{~Hz}, 2 \mathrm{H}), 3.50-3.37(\mathrm{~m}, 2 \mathrm{H}), 3.13-2.99$ $(\mathrm{m}, 4 \mathrm{H}), 2.71-2.58(\mathrm{~m}, 2 \mathrm{H}), 1.82-1.75(\mathrm{~m}, 4 \mathrm{H}), 1.72(\mathrm{dt}, J=14.5,6.6 \mathrm{~Hz}, 2 \mathrm{H}), 1.62-1.59(\mathrm{~m}$, $1 \mathrm{H}), 1.44-1.36(\mathrm{~m}, 2 \mathrm{H}), 1.35-1.23(\mathrm{~m}, 6 \mathrm{H}), 0.98(\mathrm{~d}, J=6.5 \mathrm{~Hz}, 3 \mathrm{H}), 0.85(\mathrm{t}, J=6.9 \mathrm{~Hz}, 3 \mathrm{H})$; ${ }^{13} \mathrm{C}$ NMR $\left(125 \mathrm{MHz}, \mathrm{CDCl}_{3}\right) \delta 158.3,129.9,127.8,114.9,78.1,46.5,33.4,31.8,29.3,29.1,26.1$, 22.7, 14.1; ESI-HRMS $(\mathrm{M}+\mathrm{H})^{+} m / z$ calcd for $\mathrm{C}_{21} \mathrm{H}_{36} \mathrm{NO} 318.2797$, found 318.2712.

(1-(4-(Heptyloxy)phenethyl)piperidin-3-yl)methanol (8): ${ }^{1} \mathrm{H}$ NMR (500 MHz, $\left.\mathrm{CDCl}_{3}\right) \delta 7.04$ $(\mathrm{d}, J=8.6 \mathrm{~Hz}, 2 \mathrm{H}), 6.75(\mathrm{~d}, J=8.7 \mathrm{~Hz}, 2 \mathrm{H}), 3.86(\mathrm{t}, J=6.6 \mathrm{~Hz}, 2 \mathrm{H}), 3.62(\mathrm{dd}, J=11.3,4.5 \mathrm{~Hz}$, 2H), 3.48-3.41 (m, 1H), 3.39-3.29 (m, 1H), 3.08-2.96 (m, 4H), 2.69-2.54 (m, 2H), 2.33-2.21 (m, $2 \mathrm{H}), 2.01(\mathrm{ddd}, J=26.2,8.0,5.5 \mathrm{~Hz}, 1 \mathrm{H}), 1.88-1.80(\mathrm{~m}, 1 \mathrm{H}), 1.73(\mathrm{dt}, J=14.6,6.6 \mathrm{~Hz}, 3 \mathrm{H})$, $1.41(\mathrm{dq}, J=9.1,6.7 \mathrm{~Hz}, 2 \mathrm{H}), 1.35-1.22(\mathrm{~m}, 6 \mathrm{H}), 0.87(\mathrm{t}, J=6.9 \mathrm{~Hz}, 3 \mathrm{H}) ;{ }^{13} \mathrm{C} \mathrm{NMR}(125 \mathrm{MHz}$, $\left.\mathrm{CDCl}_{3}\right) \delta 158.2,129.9,125.9,114.9,68.1,64.2,59.4,56.0,53.4,31.9,29.8,29.4,29.2,26.1,22.7$, 21.4, 14.2; ESI-HRMS $(\mathrm{M}+\mathrm{H})^{+} \mathrm{m} / z$ calcd for $\mathrm{C}_{21} \mathrm{H}_{36} \mathrm{NO}_{2} 334.2746$, found 334.2762.

1-(4-(Heptyloxy)phenethyl)piperazine (9): ${ }^{1} \mathrm{H}$ NMR $\left(500 \mathrm{MHz}, \mathrm{CDCl}_{3}\right) \delta 7.02$ (d, J = 8.2 Hz, $2 \mathrm{H}), 6.79(\mathrm{~d}, J=8.4 \mathrm{~Hz}, 2 \mathrm{H}), 3.90(\mathrm{t}, J=6.6 \mathrm{~Hz}, 2 \mathrm{H}), 3.32,-3.20(\mathrm{~m}, 4 \mathrm{H}), 2.83-2.71(\mathrm{~m}, 4 \mathrm{H})$, 2.67-2.55 (m, 4H), 1.79-1.68 (m, 2H), 1.47-1.38 (m, 2H), 1.38-1.21 (m, 6H), $0.88(\mathrm{t}, J=6.7 \mathrm{~Hz}$, $3 \mathrm{H}) ;{ }^{13} \mathrm{C}$ NMR $\left(125 \mathrm{MHz}, \mathrm{CDCl}_{3}\right) \delta 157.6,129.2,125.9,114.6,68.1,59.9,49.6,43.7,31.9,29.4$, 29.2, 26.1, 22.7, 21.4, 14.2; ESI-HRMS $(\mathrm{M}+\mathrm{H})^{+} m / z$ calcd for $\mathrm{C}_{19} \mathrm{H}_{33} \mathrm{~N}_{2} \mathrm{O} 305.2593$, found 305.2587 .

2-(4-(4-(Heptyloxy)phenethyl)piperazin-1-yl)ethanol (10): ${ }^{1} \mathrm{H}$ NMR (500 MHz, $\left.\mathrm{CDCl}_{3}\right)$ $\delta 7.06(\mathrm{~d}, J=8.6 \mathrm{~Hz}, 2 \mathrm{H}), 6.79(\mathrm{~d}, J=8.6 \mathrm{~Hz}, 2 \mathrm{H}), 3.89(\mathrm{t}, J=6.6 \mathrm{~Hz}, 2 \mathrm{H}), 3.72-3.65(\mathrm{~m}, 2 \mathrm{H})$, 2.79-2.59 (m, 14H), 1.78-1.69 (m, 2H), 1.46-1.36 (m, 2H), 1.36-1.21 (m, 6H), $0.86(\mathrm{t}, J=6.9$ $\mathrm{Hz}, 3 \mathrm{H}) ;{ }^{13} \mathrm{C}$ NMR $\left(125 \mathrm{MHz}, \mathrm{CDCl}_{3}\right) \delta 157.7,129.6,126.0,114.6,68.1,60.2,59.4,57.5,52.6$, $52.4,32.3,31.9,29.4,29.1,26.1,22.7,14.2$; ESI-HRMS $(\mathrm{M}+\mathrm{H})^{+} m / z$ calcd for $\mathrm{C}_{21} \mathrm{H}_{37} \mathrm{~N}_{2} \mathrm{O}_{2}$ 349.2855 , found 349.2817 .

(R)-4-(2-(2-(Hydroxymethyl)pyrrolidin-1-yl)ethyl)phenyl benzenesulfonate (11): ${ }^{1} \mathrm{H}$ NMR $\left(500 \mathrm{MHz}, \mathrm{CDCl}_{3}\right) \delta$ 7.84-7.76 (m, 2H), 7.68-7.61 (m, 1H), 7.55-7.47 (m, 2H), $7.11(\mathrm{~d}$, $J=8.5 \mathrm{~Hz}, 2 \mathrm{H}), 6.87(\mathrm{~d}, J=8.6 \mathrm{~Hz}, 2 \mathrm{H}), 3.71(\mathrm{dd}, J=12.0,3.1 \mathrm{~Hz}, 1 \mathrm{H}), 3.59(\mathrm{dd}, J=12.1$, $4.7 \mathrm{~Hz}, 1 \mathrm{H}), 3.48(\mathrm{dd}, J=9.6,4.4 \mathrm{~Hz}, 1 \mathrm{H}), 3.24-3.13(\mathrm{~m}, 1 \mathrm{H}), 3.02(\mathrm{dd}, J=19.1,9.9 \mathrm{~Hz}$, 2H), $2.91(\mathrm{ddd}, J=13.6,10.5,5.1 \mathrm{~Hz}, 1 \mathrm{H}), 2.84-2.73(\mathrm{~m}, 1 \mathrm{H}), 2.58(\mathrm{dd}, J=16.8,8.3 \mathrm{~Hz}, 1 \mathrm{H})$, 2.04-1.80 (m, 4H); $\left.{ }^{13} \mathrm{C} \mathrm{NMR} \mathrm{(125} \mathrm{MHz,} \mathrm{CDCl}_{3}\right) \delta 148.3,135.4,134.3,130.0,129.2,128.5,122.6$, 
$67.9,61.3,56.8,54.5,33.1,29.8,27.0,23.9$; ESI-HRMS $(\mathrm{M}+\mathrm{H})^{+} \mathrm{m} / z$ calcd for $\mathrm{C}_{19} \mathrm{H}_{24} \mathrm{NO}_{4} \mathrm{~S}$ 362.1426, found 362.1404.

4-(2-(Piperidin-1-yl)ethyl)phenyl benzenesulfonate (12): ${ }^{1} \mathrm{H}$ NMR $\left(500 \mathrm{MHz}, \mathrm{CDCl}_{3}\right) \delta$ 7.84-7.78 (m, 2H), 7.69-7.62 (m, 1H), $7.50(\mathrm{dd}, J=11.1,4.8 \mathrm{~Hz}, 2 \mathrm{H}), 7.11(\mathrm{~d}, J=8.5 \mathrm{~Hz}, 2 \mathrm{H})$, $6.87(\mathrm{~d}, J=8.5 \mathrm{~Hz}, 2 \mathrm{H}), 2.89(\mathrm{dd}, J=10.1,6.5 \mathrm{~Hz}, 2 \mathrm{H}), 2.67(\mathrm{dd}, J=7.2,3.6 \mathrm{~Hz}, 2 \mathrm{H}), 2.65-2.56$ $(\mathrm{m}, 4 \mathrm{H}), 1.77-1.69(\mathrm{~m}, 4 \mathrm{H}), 1.56-1.44(\mathrm{~m}, 2 \mathrm{H}) ;{ }^{13} \mathrm{C} \mathrm{NMR}\left(125 \mathrm{MHz}, \mathrm{CDCl}_{3}\right) \delta 148.1,135.5$, $134.3,130.1,129.2,128.5,122.5,60.3,54.3,32.0,25.0,23.7$; ESI-HRMS $(\mathrm{M}+\mathrm{H})^{+} \mathrm{m} / z$ calcd for $\mathrm{C}_{19} \mathrm{H}_{24} \mathrm{NO}_{3} \mathrm{~S}$ 346.1477, found 346.1439 .

4-(2-(4-Hydroxypiperidin-1-yl)ethyl)phenyl benzenesulfonate (13): ${ }^{1} \mathrm{H}$ NMR (500 MHz, $\left.\mathrm{CDCl}_{3}\right) \delta 7.82(\mathrm{dd}, J=8.3,1.0 \mathrm{~Hz}, 2 \mathrm{H}), 7.69-7.62(\mathrm{~m}, 1 \mathrm{H}), 7.52(\mathrm{t}, J=8.0 \mathrm{~Hz}, 2 \mathrm{H}), 7.12(\mathrm{~d}$, $J=8.5 \mathrm{~Hz}, 2 \mathrm{H}), 6.88(\mathrm{~d}, J=8.5 \mathrm{~Hz}, 2 \mathrm{H}), 3.93-3.82(\mathrm{~m}, 1 \mathrm{H}), 2.98(\mathrm{dd}, J=13.4,5.5 \mathrm{~Hz}, 2 \mathrm{H})$, 2.95-2.87 (m, 2H), 2.79-2.70 (m, 2H), 2.67-2.53 (m, 2H), 2.13-2.03 (m, 2H), 1.77-1.68 (m, 2H); ${ }^{13} \mathrm{C}$ NMR $\left(125 \mathrm{MHz}, \mathrm{CDCl}_{3}\right) \delta 148.2,135.5,134.3,130.0,129.2,128.7,122.6,65.0,59.4,50.1$, 44.2, 32.7, 31.9; ESI-HRMS $(\mathrm{M}+\mathrm{H})^{+} \mathrm{m} / \mathrm{z}$ calcd for $\mathrm{C}_{19} \mathrm{H}_{24} \mathrm{NO}_{4} \mathrm{~S} 362.1426$, found 362.1492 .

4-(2-Morpholinoethyl)phenyl benzenesulfonate (14): ${ }^{1} \mathrm{H}$ NMR $\left(500 \mathrm{MHz}, \mathrm{CDCl}_{3}\right) \delta 7.81$ (dd, $J=8.5,1.2 \mathrm{~Hz}, 2 \mathrm{H}), 7.64(\mathrm{ddt}, J=8.7,7.2,1.2 \mathrm{~Hz}, 1 \mathrm{H}), 7.54-7.48(\mathrm{~m}, 2 \mathrm{H}), 7.09(\mathrm{~d}, J=8.6 \mathrm{~Hz}$, $2 \mathrm{H}), 6.87(\mathrm{~d}, J=8.6 \mathrm{~Hz}, 2 \mathrm{H}), 3.75-3.65(\mathrm{~m}, 4 \mathrm{H}), 2.73(\mathrm{dd}, J=9.4,6.7 \mathrm{~Hz}, 2 \mathrm{H}), 2.54-2.50$ $(\mathrm{m}, 2 \mathrm{H}), 2.47(\mathrm{dd}, J=8.9,4.7 \mathrm{~Hz}, 4 \mathrm{H}) ;{ }^{13} \mathrm{C}$ NMR $\left(125 \mathrm{MHz}, \mathrm{CDCl}_{3}\right) \delta 147.9,139.4,135.6$, $134.2,129.9,129.2,128.6,122.3,67.0,60.5,53.7,32.7$; ESI-HRMS $(\mathrm{M}+\mathrm{H})^{+} \mathrm{m} / z$ calcd for $\mathrm{C}_{18} \mathrm{H}_{22} \mathrm{NO}_{4} \mathrm{~S} 348.1270$, found 348.1217 .

(S)-4-(2-(2-(Hydroxymethyl)pyrrolidin-1-yl)ethyl)phenyl benzenesulfonate (15): ${ }^{1} \mathrm{H}$ NMR $\left(500 \mathrm{MHz}, \mathrm{CDCl}_{3}\right) \delta 7.84-7.76(\mathrm{~m}, 2 \mathrm{H}), 7.69-7.60(\mathrm{~m}, 1 \mathrm{H}), 7.50(\mathrm{dd}, J=8.4,7.8 \mathrm{~Hz}, 2 \mathrm{H}), 7.11$ $(\mathrm{d}, J=8.9 \mathrm{~Hz}, 2 \mathrm{H}), 6.88(\mathrm{~d}, J=8.8 \mathrm{~Hz}, 2 \mathrm{H}), 3.72(\mathrm{dd}, J=12.6,3.1 \mathrm{~Hz}, 1 \mathrm{H}), 3.66-3.57(\mathrm{~m}, 1 \mathrm{H})$, 3.54-3.42 (m, 1H), 3.27-3.15 (m, 1H), 3.10-2.98 (m, 2H), $2.91(\mathrm{ddd}, J=11.2,8.4,5.2 \mathrm{~Hz}, 1 \mathrm{H})$, 2.82-2.73 (m, 1H), 2.63-2.52 (m, 1H), 2.04-1.79 (m, 4H); $\left.{ }^{13} \mathrm{C} \mathrm{NMR} \mathrm{(125} \mathrm{MHz,} \mathrm{CDCl}\right) \delta 148.3$, 135.4, 134.3, 129.9, 129.2, 128.6, 122.7, 68.0, 61.4, 56.9, 54.5, 33.1, 29.8, 27.0, 23.9; ESI-HRMS $(\mathrm{M}+\mathrm{H})^{+} \mathrm{m} / \mathrm{z}$ calcd for $\mathrm{C}_{19} \mathrm{H}_{24} \mathrm{NO}_{4} \mathrm{~S} 362.1426$, found 362.1427 .

4-(2-(4-(Hydroxymethyl)piperidin-1-yl)ethyl)phenyl benzenesulfonate (16): ${ }^{1} \mathrm{H} \mathrm{NMR}$ (500 MHz, $\left.\mathrm{CDCl}_{3}\right) \delta 7.84-7.78(\mathrm{~m}, 2 \mathrm{H}), 7.65(\mathrm{ddd}, J=7.2,2.4,1.2 \mathrm{~Hz}, 1 \mathrm{H}), 7.54-7.48(\mathrm{~m}, 2 \mathrm{H}), 7.12(\mathrm{~d}$, $J=8.5 \mathrm{~Hz}, 2 \mathrm{H}), 6.87(\mathrm{~d}, J=8.6 \mathrm{~Hz}, 2 \mathrm{H}), 3.49(\mathrm{~d}, J=5.3 \mathrm{~Hz}, 2 \mathrm{H}), 3.29(\mathrm{~d}, J=11.6 \mathrm{~Hz}, 2 \mathrm{H})$, $2.96(\mathrm{dd}, J=10.5,5.7 \mathrm{~Hz}, 2 \mathrm{H}), 2.83(\mathrm{dd}, J=11.3,5.2 \mathrm{~Hz}, 2 \mathrm{H}), 2.41(\mathrm{t}, J=9.8 \mathrm{~Hz}, 2 \mathrm{H}), 1.84(\mathrm{~d}$, $J=10.6 \mathrm{~Hz}, 2 \mathrm{H}), 1.66-1.55(\mathrm{~m}, 3 \mathrm{H}) ;{ }^{13} \mathrm{C}$ NMR $\left(125 \mathrm{MHz}, \mathrm{CDCl}_{3}\right) \delta 148.3,135.4,134.4,130.1$, $129.3,128.5,122.6,66.7,59.2,53.2,37.3,31.3,29.8,27.2$; ESI-HRMS $(\mathrm{M}+\mathrm{H})^{+} \mathrm{m} / z$ calcd for $\mathrm{C}_{20} \mathrm{H}_{26} \mathrm{NO}_{4} \mathrm{~S} 376.1583$, found 376.1523 .

4-(2-(4-Methylpiperidin-1-yl)ethyl)phenyl benzenesulfonate (17): ${ }^{1} \mathrm{H}$ NMR (500 MHz, $\left.\mathrm{CDCl}_{3}\right) \delta 7.83-7.79(\mathrm{~m}, 2 \mathrm{H}), 7.65(\mathrm{td}, J=7.6,1.1 \mathrm{~Hz}, 1 \mathrm{H}), 7.54-7.48(\mathrm{~m}, 2 \mathrm{H}), 7.12(\mathrm{~d}, J=8.4 \mathrm{~Hz}$, $2 \mathrm{H}), 6.87(\mathrm{~d}, J=8.6 \mathrm{~Hz}, 2 \mathrm{H}), 3.16(\mathrm{~d}, J=11.5 \mathrm{~Hz}, 2 \mathrm{H}), 2.94(\mathrm{dd}, J=11.3,5.4 \mathrm{~Hz}, 2 \mathrm{H}), 2.74(\mathrm{dd}$, $J=10.1,6.4 \mathrm{~Hz}, 2 \mathrm{H}), 2.27(\mathrm{t}, J=11.1 \mathrm{~Hz}, 2 \mathrm{H}), 1.71(\mathrm{~d}, J=11.8 \mathrm{~Hz}, 2 \mathrm{H}), 1.52(\mathrm{ddd}, J=25.6$, $8.9,0.9 \mathrm{~Hz}, 3 \mathrm{H}), 0.96(\mathrm{~d}, J=6.0 \mathrm{~Hz}, 3 \mathrm{H}) ;{ }^{13} \mathrm{C} \mathrm{NMR}\left(125 \mathrm{MHz}, \mathrm{CDCl}_{3}\right) \delta 148.2,135.5,134.3$, $130.1,129.2,128.6,122.5,59.6,53.5,32.7,31.7,30.1,21.4$; ESI-HRMS $(\mathrm{M}+\mathrm{H})^{+} \mathrm{m} / z$ calcd for $\mathrm{C}_{20} \mathrm{H}_{26} \mathrm{NO}_{3} \mathrm{~S} 360.1633$, found 360.1634 .

4-(2-(3-(Hydroxymethyl)piperidin-1-yl)ethyl)phenyl benzenesulfonate (18): ${ }^{1} \mathrm{H}$ NMR (500 MHz, $\left.\mathrm{CDCl}_{3}\right) \delta 7.88-7.80(\mathrm{~m}, 2 \mathrm{H}), 7.65(\mathrm{ddt}, J=8.7,7.2,1.2 \mathrm{~Hz}, 1 \mathrm{H}), 7.54-7.47(\mathrm{~m}, 2 \mathrm{H}), 7.08(\mathrm{~d}$, $J=8.6 \mathrm{~Hz}, 2 \mathrm{H}), 6.86(\mathrm{~d}, J=8.6 \mathrm{~Hz}, 2 \mathrm{H}), 3.62(\mathrm{dd}, J=10.8,5.0 \mathrm{~Hz}, 1 \mathrm{H}), 3.52-3.43(\mathrm{~m}, 1 \mathrm{H})$, $3.07(\mathrm{~d}, J=10.3 \mathrm{~Hz}, \mathrm{OH}), 2.89-2.79(\mathrm{~m}, 2 \mathrm{H}), 2.68-2.62(\mathrm{~m}, 2 \mathrm{H}), 2.61-2.47(\mathrm{~m}, 4 \mathrm{H}), 2.28(\mathrm{t}$, $J=10.0 \mathrm{~Hz}, 1 \mathrm{H}), 2.21-2.11(\mathrm{~m}, 1 \mathrm{H}), 1.96-1.86(\mathrm{~m}, 1 \mathrm{H}), 1.83-1.75(\mathrm{~m}, 1 \mathrm{H}), 1.73-1.64(\mathrm{~m}, 1 \mathrm{H})$; ${ }^{13} \mathrm{C}$ NMR $\left(125 \mathrm{MHz}, \mathrm{CDCl}_{3}\right) \delta 148.1,138.7,135.5,134.3,130.1,129.2,128.5,125.9,122.4$, $66.4,60.3,57.1,54.2,37.7,32.2,26.9,24.1$; ESI-HRMS $(\mathrm{M}+\mathrm{H})^{+} m / z$ calcd for $\mathrm{C}_{20} \mathrm{H}_{26} \mathrm{NO}_{4} \mathrm{~S}$ 376.1583 , found 376.1555 .

4-(2-(Piperazin-1-yl)ethyl)phenyl benzenesulfonate (19): ${ }^{1} \mathrm{H}$ NMR $\left(500 \mathrm{MHz}, \mathrm{CDCl}_{3}\right) \delta$ 7.89-7.81 (m, 2H), 7.68-7.61 (m, 1H), $7.51(\mathrm{t}, J=8.1 \mathrm{~Hz}, 2 \mathrm{H}), 7.05(\mathrm{~d}, J=8.9 \mathrm{~Hz}, 2 \mathrm{H}), 6.87$ 
$(\mathrm{d}, J=8.9 \mathrm{~Hz}, 2 \mathrm{H}), 3.25-3.15(\mathrm{~m}, 4 \mathrm{H}), 2.69(\mathrm{dd}, J=11.6,4.4 \mathrm{~Hz}, 8 \mathrm{H}){ }^{13} \mathrm{C} \mathrm{NMR}(125 \mathrm{MHz}$, $\left.\mathrm{CDCl}_{3}\right) \delta 148.1,138.8,135.6,134.3,130.6,129.8,129.3,129.0,125.9,122.4,59.4,50.1,44.1$, 32.6; ESI-HRMS $(\mathrm{M}+\mathrm{H})^{+} m / z$ calcd for $\mathrm{C}_{18} \mathrm{H}_{23} \mathrm{~N}_{2} \mathrm{O}_{3} \mathrm{~S} 347.1429$, found 347.1484.

4-(2-(4-(2-Hydroxyethyl)piperazin-1-yl)ethyl)phenyl benzenesulfonate (20): ${ }^{1} \mathrm{H}$ NMR (500 MHz, $\left.\mathrm{CDCl}_{3}\right) \delta 7.80(\mathrm{dd}, J=8.5,1.2 \mathrm{~Hz}, 2 \mathrm{H}), 7.67-7.59(\mathrm{~m}, 1 \mathrm{H}), 7.49(\mathrm{dd}, J=8.3,7.5 \mathrm{~Hz}, 2 \mathrm{H}), 7.07$ $(\mathrm{d}, J=8.6 \mathrm{~Hz}, 2 \mathrm{H}), 6.85(\mathrm{~d}, J=8.6 \mathrm{~Hz}, 2 \mathrm{H}), 3.64-3.55(\mathrm{~m}, 2 \mathrm{H}), 2.76-2.65(\mathrm{~m}, 4 \mathrm{H}), 2.58-2.43$ $(\mathrm{m}, 10 \mathrm{H}) ;{ }^{13} \mathrm{C}$ NMR $\left(125 \mathrm{MHz}, \mathrm{CDCl}_{3}\right) \delta 147.9,139.5,135.6,134.2,130.0,129.2,128.6,122.3$, 60.0, 59.4, 57.8, 53.1, 52.9, 32.9; ESI-HRMS $(\mathrm{M}+\mathrm{H})^{+} \mathrm{m} / z$ calcd for $\mathrm{C}_{20} \mathrm{H}_{27} \mathrm{~N}_{2} \mathrm{O}_{4} \mathrm{~S} 391.1692$, found 391.1602.

\subsection{Biology}

\subsubsection{Chemicals and Reagents}

DMEM, RPMI, trypsin-EDTA $0.25 \%$ and penicillin-streptomycin (PS) was purchased from GE Healthcare Life Sciences Hyclone Laboratories (Pittsburg, PA, USA). Fetal bovine serum (FBS) was received from Gibco (Thermo Fisher Scientific Inc., Walthem, MA, USA). ApoScan $^{\mathrm{TM}}$ annexin V-FITC was obtained from BioBud (Cat. No.: LS-02-100, Seongnam, Gyeonggi-do, Korea). MTT cell viability assay kit EZ-CYTOX was acquired from Do-GenBio Co. Ltd. (Seoul, Korea). PP2A activity kit was purchased from Millipore Corporation (Billerica, MA, USA). Antibodies against AKT (9272), pAKT (Thr308) (13038), Caspase-3 (9662), BAX (2772), and PARP (9542), and Bcl-2 (3498) were provided from Cell Signaling Technology (Danvers, MA, USA). $\beta$-actin (sc-47778), cytochrome-c (sc-13156), ERK 1/2 (sc-514302), pERK (Thr202/Tyr204) (sc-136521), and HRP-conjugated anti-mouse and antirabbit antibodies were received from Santa Cruz Biotechnology (Dallas, TX, USA). SK1 (ab71700) and SK1 (ab264042) antibodies were acquired from Abcam (Cambridge, UK). Protein marker, protease, and phosphatase inhibitor cocktail were purchased from Thermo Fisher Scientific (Waltham, MA, USA). ECL Solution for western blotting imaging was received from Millipore Corporation (Burlington, MA, USA).

\subsubsection{Cell Culture and MTT Cell Viability Assay}

The HT29 and HCT116 cells (human colon cancer), AGS (human gastric cancer), and MIA PaCa-2 cells (human pancreatic cancer) were purchased from Korean Cell Line Bank (Seoul, Korea). Cancer cells were maintained in RPMI (HT29 and AGS) and DMEM (HCT116 and MIA PaCa-2) culture media supplemented with 10\% fetal bovine serum (FBS) and $100 \mathrm{U} / \mathrm{mL}$ penicillin and streptomycin at $37{ }^{\circ} \mathrm{C}$ in a $95 \%$ humidified incubator containing $5 \% \mathrm{CO}_{2}$. The cytotoxic effect of the compounds was assessed using the MTT cell viability assay. Briefly, $3 \times 10^{3}$ cells/well were grown in 96-well plates for $24 \mathrm{~h}$. After treatment with desired concentration of respective compounds for $24 \mathrm{~h}$ or $48 \mathrm{~h}$, the EZ-CYTOTOX $(10 \mu \mathrm{M})$ reagent was added in each well and incubated for $90 \mathrm{~min}$. The absorbance was measured at $450 \mathrm{~nm}$ wavelength using Skanlt software 5.0 (Thermo Scientific, Waltham, MA, USA) installed on a Multiskan GO (Thermo Scientific, Waltham, MA, USA) spectrophotometer. Each experiment was independently repeated three times $(n=12)$.

\subsubsection{Clonogenic Assay}

Cell proliferation was assayed by in vitro clonogenic assay. To perform the clonogenic assay, HT29 and HCT116 cells (1000 cells/well) were grown in 6-well plates for $24 \mathrm{~h}$. Cells were treated with compound 10 and FTY720 in different concentrations for $12 \mathrm{~h}$ and changed fresh medium. Colonies were allowed to grow for two weeks by changing to a fresh medium every 3 days. Colonies were stained with $0.1 \%$ crystal violet prepared in $25 \%$ keto-glutaraldehyde for $30 \mathrm{~min}$ and washed with running water and photographed with Canon Rebel T6i (Tokyo, Kanto, Japan). Colonies were counted using Image J software 
version 1.53i, National Institutes of Health, Bethesda, MD, USA). Plating efficiency (PE) and surviving fraction (SF) was calculated using the following formula.

$$
\begin{aligned}
\text { [Plating efficiency }(\mathrm{PE})] & =\frac{\text { Number of colony count in control }}{\text { Number of cell seeded }} \\
\text { [Surviving Fraction] } & =\frac{\text { Number of colony count }}{\text { Number of cell seeded } \times \mathrm{PE}}
\end{aligned}
$$

\subsubsection{Annexin V-FITC Staining}

After treating HT29 and HCT116 cells with compounds 10, 11, 13 and FTY720 according to the manufacturer's instruction, the annexin V and PI staining technique was employed to determine apoptosis in the cells. Briefly, cells $\left(2.5 \times 10^{5}\right.$ cells/well) were seeded in 12-well plates and treated with 10 and/or $20 \mu \mathrm{M}$ of compounds for $24 \mathrm{~h}$. Cells were collected using trypsin-EDTA and stained with annexin V-FITC dye for $15 \mathrm{~min}$ at room temperature, followed by PI staining for $20 \mathrm{~min}$ and analyzed by flow cytometer (MACSQuant Analyzer 10; Miltenyi Biotec, Bergisch Gladbach, Germany). The data was analyzed using MACSQuantify ${ }^{\mathrm{TM}}$ version 2.8 software (Miltenyi Biotec, Bergisch Gladbach, Germany) and presented as early apoptosis, late apoptosis, or combined apoptosis percentage. Each experiment was repeated three times independently $(n=6)$.

2.2.5. Mitochondrial Outer Membrane Potential (MOMP) Determination by JC-10 Staining

To access the mechanism of cell death, mitochondrial outer membrane potential (MOMP) was measured using JC-10 cationic dye. HT29 and HCT116 cells $\left(2.5 \times 10^{5}\right.$ cells/well) were seeded in 12-well plates and treated with a test compound for $24 \mathrm{~h}$, collected in $1.5 \mathrm{~mL}$ microtubes using trypsin-EDTA, washed with $1 \times$ cold PBS, and stained with JC10 dye prepared in HBSS solution $\left(0.14 \mathrm{M} \mathrm{NaCl}, 0.005 \mathrm{M} \mathrm{KCl}, 0.001 \mathrm{M} \mathrm{CaCl}_{2}, 0.005 \mathrm{M}\right.$ $\mathrm{MgSO}_{4} .7 \mathrm{H}_{2} \mathrm{O}, 0.0004 \mathrm{M} \mathrm{MgSO}_{4}-6 \mathrm{H}_{2} \mathrm{O}, 0.0003 \mathrm{M} \mathrm{Na}_{2} \mathrm{HPO}_{4}-2 \mathrm{H}_{2} \mathrm{O}, 0.0004 \mathrm{M} \mathrm{KH}_{2} \mathrm{PO}_{4}$, $0.006 \mathrm{M}$ D-glucose, $0.004 \mathrm{M} \mathrm{NaHCO}_{3}, 0.002 \mathrm{M}$ HEPES, and $0.02 \%$ Pluronic $^{\circledR} \mathrm{F}-127$ ) for $30 \mathrm{~min}$. Samples were analyzed using MACSQuanta Analyzer 10. Cells with green and red fluorescence were plotted in a dot plot; the ratio of red to green fluorescence was calculated using MACSQuantify ${ }^{\mathrm{TM}}$ version 2.8 software and presented as MOMP of the cells. The experiment was repeated three times $(n=6)$.

\subsubsection{Western Blotting}

The cell lysate was prepared after successive treatment using mammalian protein extraction buffer (Organic buffer $+10 \mathrm{mM} \mathrm{NaCl}+$ detergent $\mathrm{pH}$ 7.5) mixed with $1 \%$ protease/phosphatase inhibitor cocktail; protein was quantified with BCA assay, boiled at $95^{\circ} \mathrm{C}$ for $10 \mathrm{~min}$ by adding sample loading buffer, separated using SDS-PAGE, and transferred into methanol-activated PVDF membrane. Primary antibodies were probed overnight in PVDF membrane at $4{ }^{\circ} \mathrm{C}$ and blocked with subsequent HRP anti-mouse and anti-rabbit secondary antibodies at room temperature. Then, membranes were washed with TBST buffer, and images were detected by Amersham Imager 680 (GE Healthcare; Leiden, WZ, The Netherlands) using ECL solution. Band intensities were analyzed and quantified using Image J software (version 1.53i).

\subsubsection{SK Activity Assay}

The effect of compounds in sphingosine kinase activity was examined using the AdapdaTM screening system (Thermo Fisher Scientific System, Waltham, MA, USA). The kinase inhibition ability of compounds 1-11 along with RB005 was measured with final concentration of $20 \mu \mathrm{M}$. The SK1 enzyme activity assay was performed using 0.04-0.16 ng SK1 enzyme, $50 \mu \mathrm{M}$ of sphingosine lipid substrate in reaction buffer containing HEPES $32.5 \mathrm{mM}$ (pH 7.5), BRIJ $350.005 \%, \mathrm{MgCl}_{2} 5 \mu \mathrm{M}$, and $0.5 \mathrm{mM}$ ethylene glycol-bis ( $\beta$-aminoethyl ether)- $N, N, N^{\prime}, N^{\prime}$-tetraacetic acid (EGTA), whereas 35-140 ng SK2 enzyme along with $50 \mu \mathrm{M}$ sphingosine lipid substrate was used in $32.5 \mu \mathrm{M}$ HEPES pH 7.5, $0.5 \mu \mathrm{M}$ EGTA, 
$1.5 \mu \mathrm{M} \mathrm{MgCl} 2$ buffer to detect SK2 enzyme activity. The data were presented as percentage inhibition of SK enzyme by individual compounds.

\subsubsection{S1P, Sphingosine and Ceramide ELISA}

The cellular levels of S1P, sphingosine, and ceramide were detected using an ELISA assay kit (MyBioSource, Inc., San Diego, CA, USA) according to the manufacturer's instruction. For S1P ELISA, $100 \mu \mathrm{L}$ cell lysates or standards were added in pre-coated ELISA wells, incubated for $90 \mathrm{~min}$ at $37^{\circ} \mathrm{C}$, and treated with $1 \mathrm{x}$ biotinylated anti S1P antibody for $1 \mathrm{~h}$. Following treatment of HRP conjugated secondary antibody, the substrate was added and allowed to change the color for $15 \mathrm{~min}$; then, the stop solution was added and absorbance was measured at $450 \mathrm{~nm}$ using a Multiskan GO (Thermo Scientific, Waltham, MA, USA) microplate spectrophotometer. For sphingosine, $50 \mu \mathrm{L}$ cell lysate or standards were added to the wells, a $50 \mu \mathrm{L}$ detection working solution was added, it was incubated for $1 \mathrm{~h}$ at $37^{\circ} \mathrm{C}$, a $100 \mu \mathrm{L}$ reagent $\mathrm{B}$ working solution was added, and it was incubated at $37^{\circ} \mathrm{C}$ for $45 \mathrm{~min}$. After, a substrate solution was added and incubated at $37^{\circ} \mathrm{C}$ for $20 \mathrm{~min}$ in the dark. A stop solution ( $50 \mu \mathrm{L})$ was added to each well, and optical density was measured at $450 \mathrm{~nm}$ using a microplate reader. For total ceramide ELISA assay, $100 \mu \mathrm{L}$ sample and standards were added in appropriate wells, and a $10 \mu \mathrm{L}$ balance solution was added in sample wells only. After, a $50 \mu \mathrm{L}$ conjugate solution was added in each well (except blank) plate and was gently mixed and incubated at $37^{\circ} \mathrm{C}$ for $1 \mathrm{~h}$. After incubation, $50 \mu \mathrm{L}$ substrate $\mathrm{A}$ and $\mathrm{B}$ was added to the plate and incubated at $37^{\circ} \mathrm{C}$ for $20 \mathrm{~min}$; a stop solution $(50 \mu \mathrm{L})$ was added to each well and optical density was determined at $450 \mathrm{~nm}$ using a microplate reader. The concentration of S1P, sphingosine, and ceramide were calculated as $\mathrm{ng} / \mathrm{mL}$ using respective standard curves constructed by Skanlt microplate reader software 5.0 (Thermo Scientific, Waltham, MA, USA).

\subsubsection{PP2A Assay}

The activity of PP2A was measured by using the PP2A kit according to the manufacturer's instruction. The cell lysate was incubated with anti PP2A, C subunit antibody, and protein A agarose slurry for $2 \mathrm{~h}$ at $4{ }^{\circ} \mathrm{C}$. The phosphopeptide solution $(60 \mu \mathrm{L})$ was mixed and incubated at $30^{\circ} \mathrm{C}$ for $10 \mathrm{~min}$ in a shaker. After a brief centrifuge, a $25 \mu \mathrm{L}$ sample was liquated in $\frac{1}{2}$ volume microplate and $100 \mu \mathrm{L}$ malachite green phosphate detection working solution was added. After color development, absorbance was taken at $650 \mathrm{~nm}$ in a Multiskan GO microplate reader. A phosphate standard curve was constructed using phosphate standard, and results were calculated using this standard curve. This experiment was repeated three times $(n=6)$.

\subsubsection{Inhibition of CYP Enzymes Activity by FTY720, PF-543, and Compound 10}

Human liver microsomes $(0.25 \mathrm{mg} / \mathrm{mL})$ and $0.1 \mathrm{M}$ phosphate buffer ( $\mathrm{pH} 7.4)$, substrate drug cocktail of 5 drug metabolites (phenacetin $50 \mu \mathrm{M}$, diclofenac $10 \mu \mathrm{M}$, S-mephenytoin $100 \mu \mathrm{M}$, dextromethorphan $5 \mu \mathrm{M}$, midazolam $2.5 \mu \mathrm{M}$ ), and FTY720 were added at concentrations of 0 and $10 \mu \mathrm{M}$, respectively, and incubated at $37^{\circ} \mathrm{C}$ for $5 \mathrm{~min}$ in advance, and then NADPH generation system solution was added and incubated at $37^{\circ} \mathrm{C}$ for $15 \mathrm{~min}$. Afterward, to terminate the reaction, an acetonitrile solution containing an internal standard (terfenadine) was added, centrifuged for $5 \mathrm{~min}\left(14,000 \mathrm{rpm}, 4^{\circ} \mathrm{C}\right)$, and the supernatant was injected into the LC-MS/MS system. By simultaneously analyzing metabolites, the ability of the six compounds to inhibit drug metabolism enzymes was evaluated.

Metabolites of each CYP coenzyme indicator drug generated through the above reaction were analyzed using the Shimadzu Nexera XR system and TSQ vantage (Thermo). The HPLC column was a Kinetex C18 column $\left(2.1 \times 100 \mathrm{~mm}^{2}, 2.6 \mu \mathrm{m}\right.$ particle size; Phenomenex, Torrance, CA, USA), and the mobile phase was distilled water (A) containing $0.1 \%$ formic acid and acetonitrile (B) containing $0.1 \%$ formic acid. The same gradient program was used (Table 1). The generated metabolites were quantified using MRM (Multiple Reaction Monitoring) quantification modes, and data were analyzed using Xcalibur (version 1.6.1). 
Table 1. The HPLC gradient solvent program.

\begin{tabular}{cccc}
\hline Time (min) & Flow (mL/min) & \% A & \% B \\
\hline 0 & 0.3 & 100 & 0 \\
1.0 & 0.3 & 60 & 40 \\
4.0 & 0.3 & 50 & 50 \\
4.1 & 0.3 & 100 & 0 \\
7.0 & 0.3 & 100 & 0 \\
\hline
\end{tabular}

\subsubsection{In Vitro Metabolic Stability of Compound 10, FTY720 and PF-543}

The metabolic stability of compounds 10, PF543 and FTY720 were measured using human, mice and rat liver microsomes. Microsome incubation was measured in triplicate in a $1.5 \mathrm{~mL}$ Eppendorf tube with $0.1 \mathrm{M}$ potassium phosphate buffer ( $\mathrm{pH}$ 7.4). Reduced nicotinamide adenine dinucleotide phosphate (NADPH)-dependent metabolism was evaluated by incubation of FTY720, PF-543, compound 10, or Verapamil (positive control) with pooled liver microsomes of human (HLM), rat (RLM) and mouse (MLM). It has a final volume of $100 \mathrm{~mL}$ in the presence of an NADPH regeneration system. In the final incubation mixture, $0.5 \mathrm{mg} / \mathrm{mL}$ HLM, $0.1 \mathrm{M}$ potassium phosphate buffer ( $\mathrm{pH} 7.4$ ), and NADPH regeneration system ( $1 \mathrm{mM}$ NADPH, $10 \mathrm{mM} \mathrm{MgCl}$ ) were included. In the pre-incubation mixture, HLM was added, and the mixture was run in a shaking incubator at approximately $350 \mathrm{rpm}$ and $37^{\circ} \mathrm{C}$ for 5 min under a Thermomixer (Eppendorf, Hamburg, Germany). Reactions were initiated by the addition of $1 \mathrm{mM}$ NADPH and then quenched by the addition of $40 \mu \mathrm{L}$ of ice-cold acetonitrile containing $10 \mu \mathrm{M}$ chlorpropamide (CPP) as an internal standard at 0 and $30 \mathrm{~min}$. After quenching, centrifugation of the incubation mixture was performed at $15,000 \times g$ for $5 \mathrm{~min}$ at $4{ }^{\circ} \mathrm{C}$. An aliquot of $2 \mu \mathrm{L}$ of the supernatant was injected into the LC-MS/MS system. The LC-MS/MS system was Xcalibur version 1.1.1 (Thermo Fisher Scientific Inc., Waltham, MA, USA).

\subsubsection{Statistical Analysis}

The statistical software GraphPad Prism (v.7.0, La Jolla, CA, USA) was used to analyze the data. Unless otherwise stated, all the results were reported as means $\pm \mathrm{SD}$. The data with heterogeneous variance were subjected to a non-parametric one-way ANOVA. The intergroup variation was determined using Tukey's post-procedure analysis. If $p<0.05$, the difference was considered significant.

\section{Results}

\subsection{Chemistry}

In the synthesis method, 4-(2-hydroxyethyl) phenol was used as a starting material to introduce a triphenylmethyl group, which is a bulky protecting group to synthesize compound 12, and a heptyl group was introduced at the phenol portion using potassium carbonate as a base. The protecting group of compound 13 was removed using $\mathrm{HCl}$, and then tosylation was used to synthesize compound 14. Finally, compounds 1-10 were synthesized by introducing various cyclic amines in compound 15. Compound 16, in which a benzenesulfonyl group was introduced into two hydroxyl groups with a yield of $89 \%$, was synthesized by using three equivalents of benzenesulfonyl chloride at the same starting material to introduce a tail group similar to PF-543. Using compound 16, cyclic amines were introduced in the same manner as for compounds 1-10 to obtain compounds 11-20 by a simple synthesis method (Scheme 1, Table 2). 


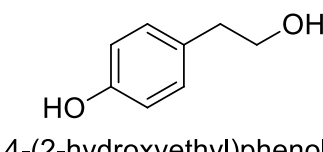

vi<smiles>C1CC1C1CC1</smiles><smiles>CCOCCc1ccc(O)cc1</smiles>

12<smiles>CCCCc1ccc(O[13CH3])cc1</smiles>

15<smiles>C[14CH2]Oc1ccc(CCO)cc1</smiles><smiles>O=S(=O)(OCCc1ccc(OS(=O)(=O)c2ccccc2)cc1)c1ccccc1</smiles><smiles>[AlH][V]</smiles><smiles>[Al]C1CCCCC1</smiles><smiles>[R]CCc1ccc(OS(=O)(=O)c2ccccc2)cc1</smiles><smiles>[R]CCc1ccc(O[GaH])cc1</smiles>

Scheme 1. Synthesis of RB005 and PF-543 derivatives 1-20. Reagents and conditions: (i) TrtCl, DMAP, $\mathrm{CH}_{2} \mathrm{Cl}_{2} /$ pyridine (1/2), rt, $1 \mathrm{~d}$, (ii) 1-bromoheptane, $\mathrm{K}_{2} \mathrm{CO}_{3}, \mathrm{DMF}, 80^{\circ} \mathrm{C}$, $12 \mathrm{~h}$, (iii) conc. $\mathrm{HCl}$, THF, $50{ }^{\circ} \mathrm{C}, 3 \mathrm{~d}$, (iv) $\mathrm{TsCl}, \mathrm{NEt}_{3}, \mathrm{CH}_{2} \mathrm{Cl}_{2}$, rt, $12 \mathrm{~h}$, (v) cyclic amines, $\mathrm{MeCN}, 40{ }^{\circ} \mathrm{C}, 12 \mathrm{~h}$, (vi) $\mathrm{PhSO}_{2} \mathrm{Cl}_{1} \mathrm{NEt}_{3}$, $\mathrm{CH}_{2} \mathrm{Cl}_{2}, \mathrm{rt}, 12 \mathrm{~h}$.

Table 2. Synthesized compounds 1-20.

\begin{tabular}{|c|c|c|}
\hline Head Group (R) & Compound No. & Compound No. \\
\hline & 1 & 11 \\
\hline & 2 & 12 \\
\hline & 3 & 13 \\
\hline & 4 & 14 \\
\hline & 5 & 15 \\
\hline & 6 & 16 \\
\hline & 7 & 17 \\
\hline & 8 & 18 \\
\hline & 9 & 19 \\
\hline 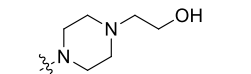 & 10 & 20 \\
\hline
\end{tabular}




\subsection{Biological Evaluations}

\subsubsection{Cytotoxic Effects of Compounds 1-10 in Human Colon Cancer Cells}

First, the synthesized compounds were separated into two sets according to their structural properties: compounds 1-10, which are analogs of RB005 (FTY720 analog), and compounds 11-20, which are analogs of PF-543. The cytotoxic effect of compounds 1-10 was observed in HT29 and HCT116 colon cancer cell lines. The cytotoxic effect of these newly synthesized compounds was compared with its structural analogs FTY720 and RB005 and widely used anti-colorectal cancer drug 5-Fluorouracil (5-FU). The initial screening of the cell viability experiment was conducted in colon cancer cell lines at concentrations of 20 and $40 \mu \mathrm{M}$. The overall cytotoxic effect of all compounds 1-10 in HT29 cells was significantly higher than in the nontreated control group (Figure 2A). Compounds 1, 2, 3, 6, 8, 9 and 10 were more cytotoxic than RB005 and 5-FU and almost similar to the effect of FTY720 in HT29 cells. Similarly, in HCT116 cells, compounds 1, 2, 6, 7, 8 and 10 have significant cytotoxic effects in both 20 and $40 \mu \mathrm{M}$ concentrations, and only $40 \mu \mathrm{M}$ concentration of compounds 3, 5 and $\mathbf{9}$ shows significant cytotoxic effect (Figure 2B).

Combining the results of all cells, we selected compound $\mathbf{1 0}$ for further experiments in colon cancer cells. Initially, the concentration-dependent cytotoxic effect of compound 10 was accessed in both HT29 and HCT116 cell lines. The bivariate correlation analysis confirmed the negative relation between compound $\mathbf{1 0}$ concentration and cell survival in both cancer cell lines (Figure 2C,D, left). The relative $\mathrm{IC}_{50}$ of compound $\mathbf{1 0}$ was measured $6.223 \mu \mathrm{M}$ and $8.694 \mu \mathrm{M}$ at $48 \mathrm{~h}$ treatment and $10.54 \mu \mathrm{M}$ and $10.88 \mu \mathrm{M}$ at $24 \mathrm{~h}$ in HT29 and HCT116 cells, respectively (Figure 2C,D, right panel and Supplementary Material Figure S1A,B). Furthermore, we performed colony formation assay after treatment of 5, 10, and $20 \mu \mathrm{M}$ of compound 10, and 5 and10 $\mu \mathrm{M}$ of FTY720 in HT29 and HCT116 cells for $24 \mathrm{~h}$. Compound 10 effectively inhibits the colony formation capacity of HT29 and HCT116 cell lines with 5, 10 and $20 \mu \mathrm{M}$ concentration in a dose-dependent manner, which is similar to the effect of 5 and $10 \mu \mathrm{M}$ concentrations of FTY720 (Figure 2E,F). These results show that compound 10 effectively inhibits colon cancer cells viability and proliferation in vitro, and this inhibitory effect is dose dependent.

3.2.2. Compound 10 Induced Apoptosis of Colorectal Cancer Cells through the Intrinsic Mitochondrial Pathway

Since the cell viability assay has confirmed that compound 10 could dose-dependently inhibit the growth of colorectal cancer cells, an annexin V assay was conducted to further identify the cell death type in colon cancer cells. Treatment of compound 10 induced apoptosis of both HT29 and HCT116 cells in a dose-dependent manner (Figure 3A). These results revealed that compound $\mathbf{1 0}$ follows the apoptotic pathway for cell death. As apoptosis has various signaling mechanisms, we additionally performed JC-10 staining of HT29 and HCT116 cells after treatment of compound $\mathbf{1 0}$ and FTY720 to determine mitochondrial outer membrane potential (MOMP). The treatment of 10 and $20 \mu \mathrm{M}$ of compound $\mathbf{1 0}$ in HT29 cells and HCT116 cells significantly reduced JC-10 dye red to green fluorescence ratio compared to nontreated control cells (Figure 3B). These results show that compound 10 reduced the MOMP, increased the mitochondrial membrane's permeability, and induced apoptosis in colorectal cancer cells. To validate the intrinsic apoptosis mechanism followed by compound 10, we analyzed the expression of apoptotic pathway-related proteins (Figure 3C). The execution of apoptosis was demonstrated with notably decreased whole PARP protein level and increased cleaved PARP level in the compound 10-treated group compared to nontreated groups. Treatment of 10 and $20 \mu \mathrm{M}$ of the compound effectively increased the cleavage of apoptosis executer protein caspase- 3 compared to nontreated control cells while pro-caspase protein level was reduced and increased the expression of proapoptotic protein BAX, whereas it decreased the expression of antiapoptotic Bcl-2 protein. These results show that compound $\mathbf{1 0}$ colorectal cancer inhibition follows the mitochondrial-mediated intrinsic apoptotic cell death pathway. 

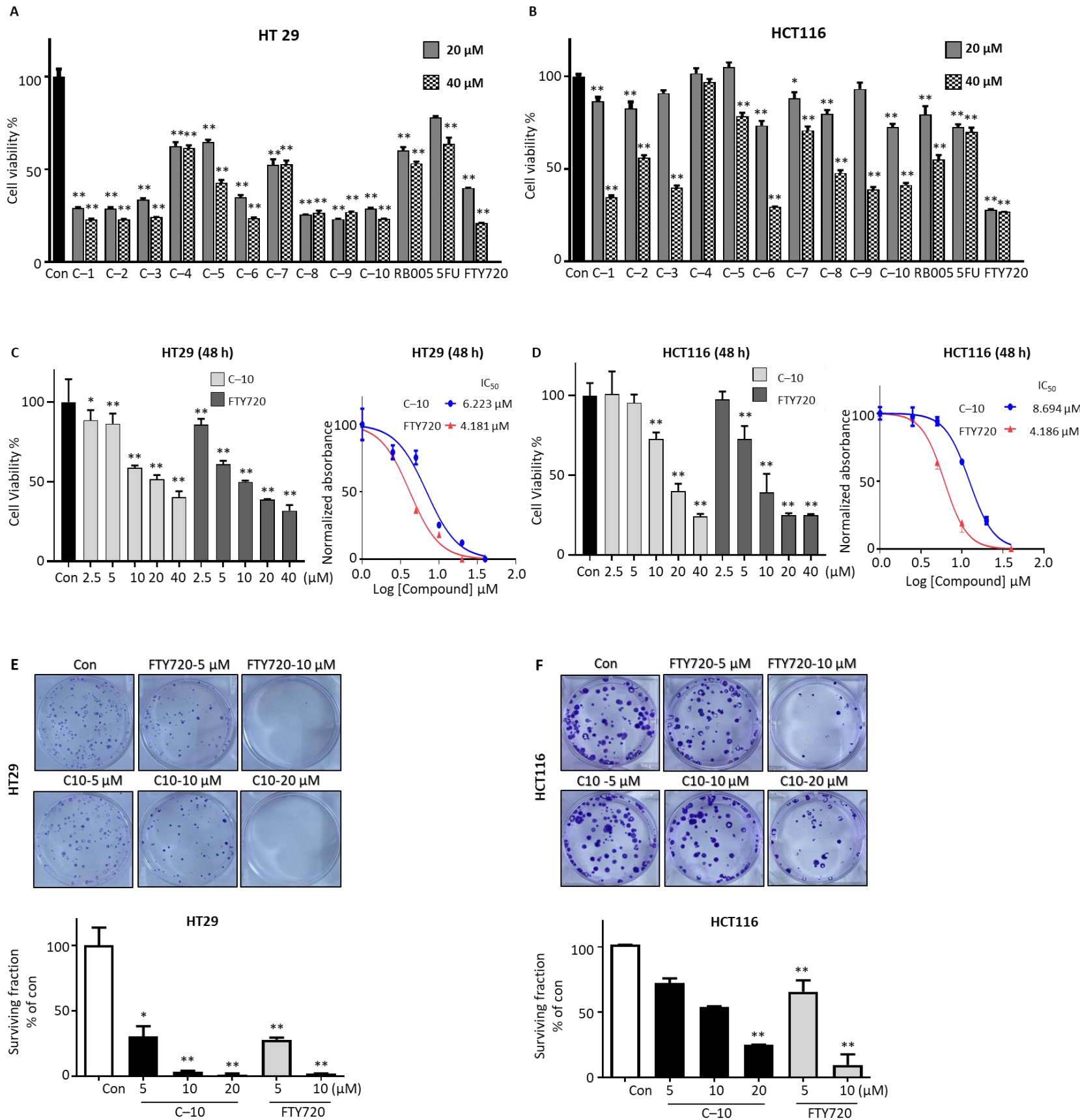

Figure 2. Compound $\mathbf{1 0}$ inhibits the growth and proliferation of colorectal cancer cells in vitro. The cell viability of (A) HT29 and (B) HCT116 with treatment of 20 and $40 \mu \mathrm{M}$ concentration of compounds 1-10 for $24 \mathrm{~h}$ was determined by MTT cell viability assay and compared with RB005, 5-FU, and FTY720. Compound 10 was selected, concentration-dependent (2.5-40 $\mu \mathrm{M})$ cell toxicity effect after $48 \mathrm{~h}$ treatment was performed, and IC $_{50}$ was determined in (C) HT29 and (D) HCT116. Cell proliferation assay was performed after treatment of compound $10(5$ and $10 \mu \mathrm{M})$ and FTY720 (5 and $10 \mu \mathrm{M})$ in (E) HT29 and (F) HCT116 cells, and the surviving fraction was calculated as described in the method. The results presented are mean \pm SD for three individual experiments. ${ }^{*} p<0.05$, ** $p<0.01$ compared with nontreated control group. 
A
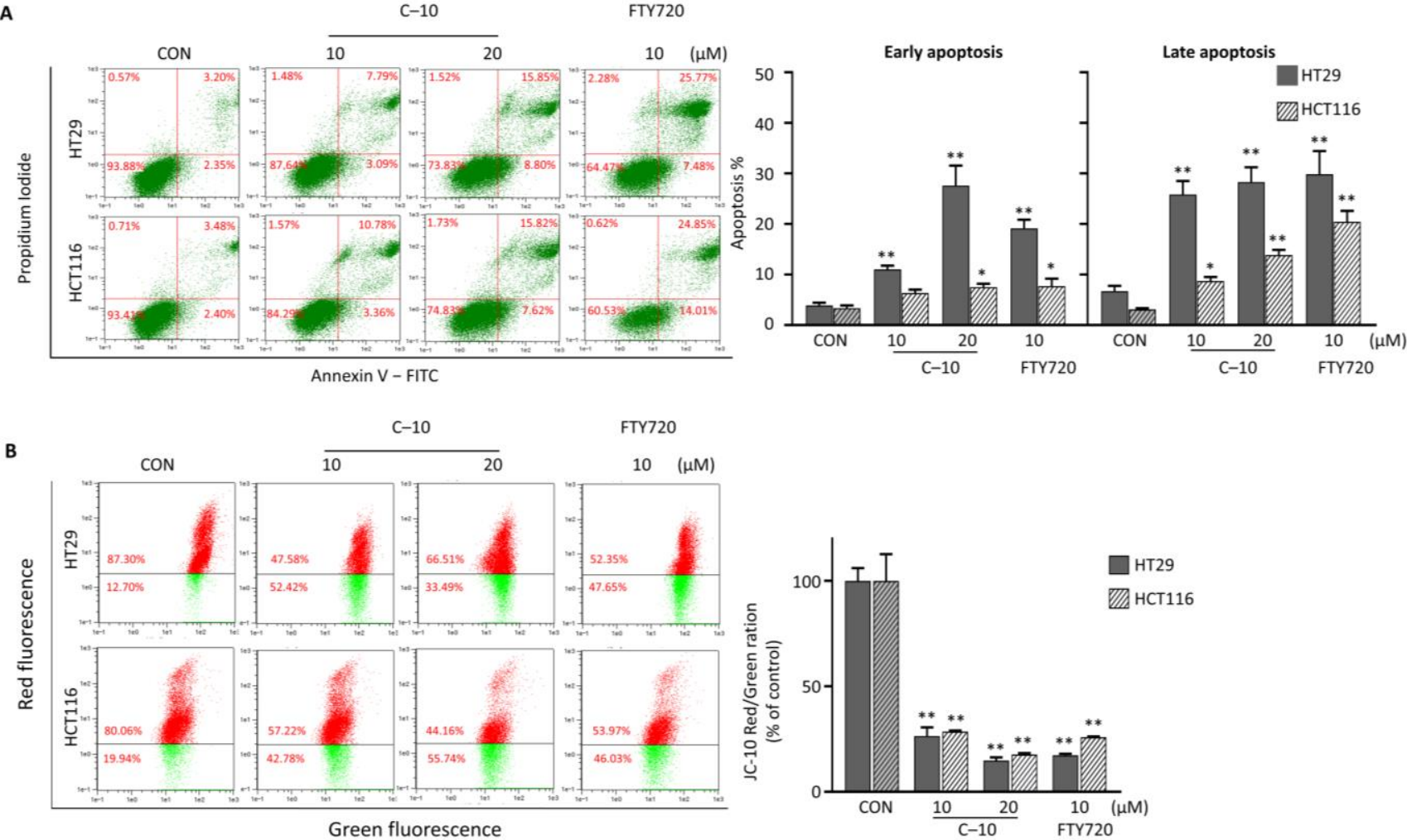

C
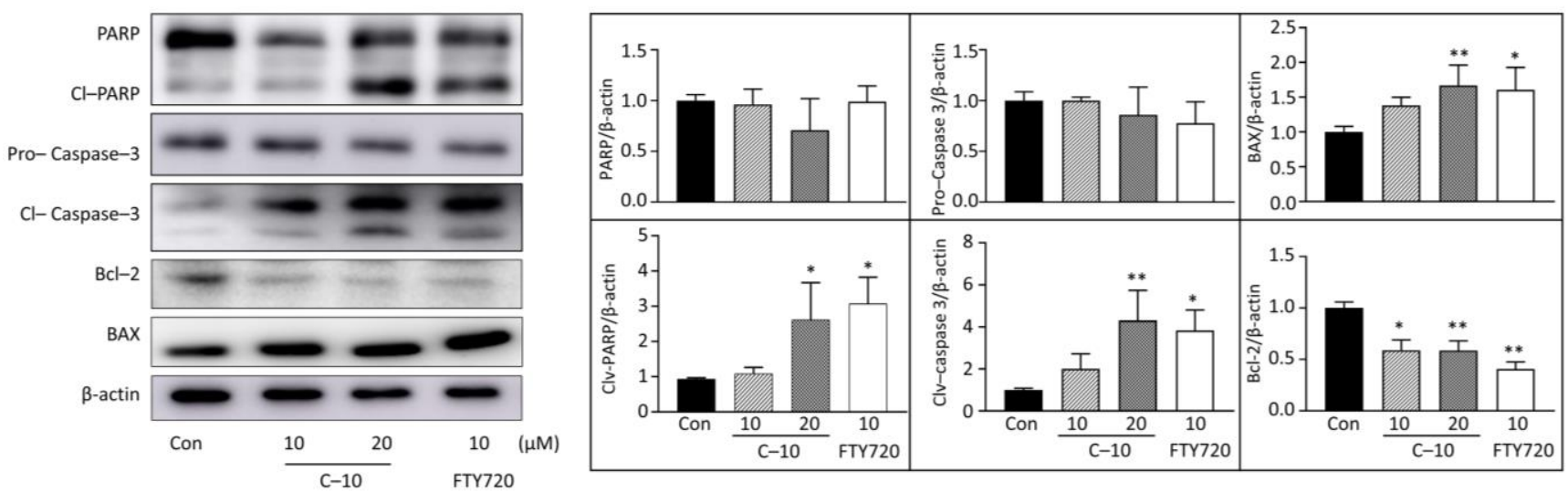

Figure 3. Compound $\mathbf{1 0}$ inhibits colorectal cancer through the intrinsic mitochondrial apoptotic pathway. (A) The HT29 and HCT116 cells were treated with the desired concentration of compound 10 and FTY720; cell apoptosis assay was performed by annexin-V assay and presented as early (left) and late (right) apoptosis. (B) Mitochondrial outer membrane potential was determined using JC-10 dye; both the samples were analyzed by flow cytometer. (C) HCT116 cells were treated with compound 10 and FTY720; the protein was extracted, and expression of proteins PARP, cleaved PARP, pro-caspase-3, cleaved caspase-3, Bcl-2, and BAX were determined by western blotting. $\beta$-actin was used as the loading control. (D) All the western blotting bands were quantified using Image-J software and expressed as protein/ $\beta$-actin compared to the nontreated control group. The result is representative of three independent experiments, and data are presented as mean $\pm \mathrm{SD} .{ }^{*} p<0.05$, ** $p<0.01$ compared with nontreated control group. 


\subsubsection{Cytotoxic Effects of Compounds 11-20 in Colorectal Cancer Cells}

We determined the cytotoxic effect of the novel synthetic compounds 11-20 with benzene sulfonyl tail structure in HT29 and HCT116. In HT29 cells, most compounds 11-20 showed a cytotoxic effect similar to that of 5-FU (Figure 4A), whereas, in HCT116 cells, the new compounds showed lower cytotoxic effects than 5-FU (Figure 4B), so the new compounds did not appear to have a marked cytotoxic effect in colon cancer cells. To confirm the cell death mechanism in HT29 cells, we chose two compounds, 11 and 13, then performed annexin V apoptosis assay in HT29 cells (Figure 4C). Treatment of both compounds 11 and $13(10$ and $20 \mu \mathrm{M})$ for $24 \mathrm{~h}$ did not significantly induce apoptosis in HT29 cells, whereas FTY720 $(10 \mu \mathrm{M})$ increased apoptosis. This shows the compounds 11-20 with benzene sulfonyl tail structure are ineffective in colorectal cancer. To examine if they exhibit anticancer activity in additional human cancer cells, we further tested the cytotoxic effects of these compounds in human pancreatic cancer MIA PaCa-2 cells and human gastric cancer AGS cells. The overall results show that compounds 1-10 were more effective than compounds 11-20 in reducing the viability of both MIA PaCa-2 and AGS cells (Supplementary Figure S2).

A

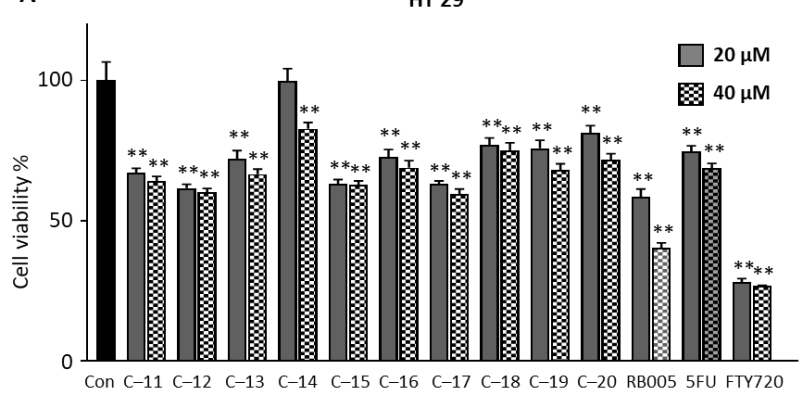

B
HCT116

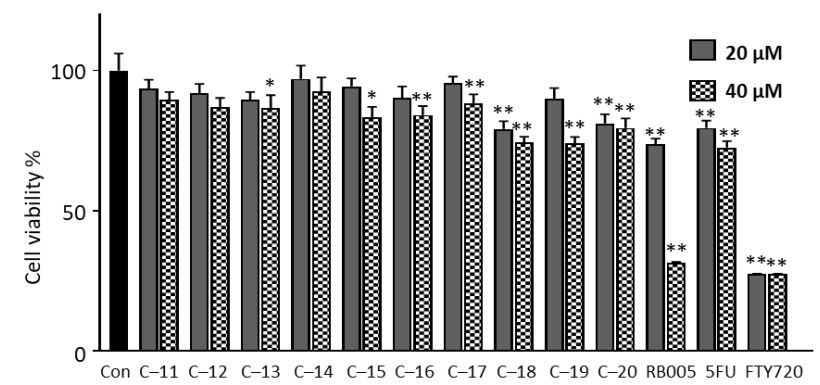

HT29
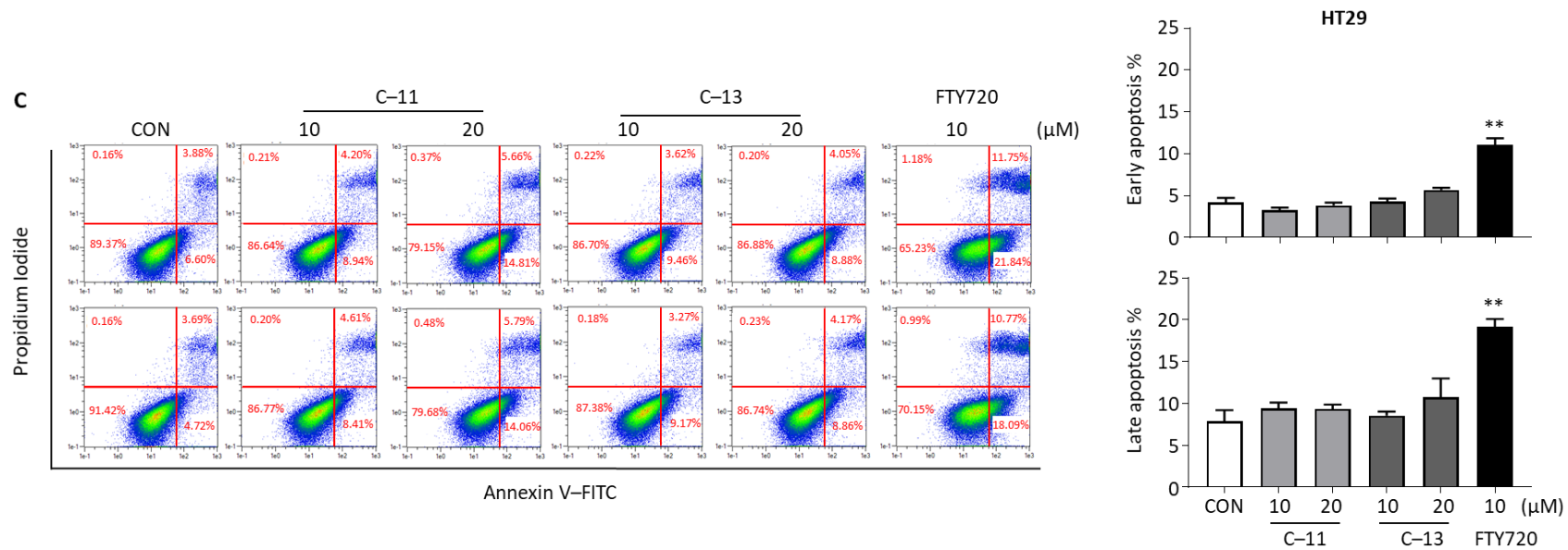

Figure 4. Effect of compounds 11-20 in colorectal cancer cells. Cytotoxicity effect of compounds 11-20 at 10 and $20 \mu \mathrm{M}$ concentration for $24 \mathrm{~h}$ in (A) HT29 and (B) HCT116 cells were determined. (C) HT29 cell apoptosis effect was analyzed by annexin V assay after treatment of compounds $\mathbf{1 1}$ and $13(10$ and $20 \mu \mathrm{M})$ and FTY720 $(10 \mu \mathrm{M})$ using flow cytometry. The result is representative of three independent experiments, and data are presented as mean $\pm \mathrm{SD} .{ }^{*} p<0.05,{ }^{* *} p<0.01$ compared with nontreated control group.

\subsubsection{SK $1 / 2$ Assay of Compounds}

We measured the SK1/2 inhibitory effect of the novel synthetic compounds 1-10 having an aliphatic chain (Figure 5A). Compared to the RB005, which is not connected by a heteroatom, the newly synthesized compounds $\mathbf{1}-\mathbf{1 0}$ increased the overall SK1/2 inhibitory effect. Compound 1, which has the same head group as PF-543, showed the 
highest SK1 inhibitory effect, and all compounds showed selectivity to SK1. In addition, the selectivity of SK1 of all compounds was increased compared to RB005. There was no difference in the SK1/2 inhibitory effect between the compounds with hydroxy in the head group (compounds 1, 3, 5, 6, 8 and 10) and the compounds without the hydroxy head group (compounds 2, 4, 7 and 9). We measured the SK1/2 inhibitory effects of compound 11 having a head group such as PF-543 and compound 13 having a head group such as RB005 at $20 \mu \mathrm{M}$ (Figure 5B). Compounds $\mathbf{1 1}$ and $\mathbf{1 3}$ showed a similar SK1 inhibitory effect and more selectivity than RB005. In particular, compound $\mathbf{1 1}$ of the head group, such as PF-543, which has the highest known SK1 inhibitory effect, showed a three-fold higher SK1 inhibitory effect than RB005.

A

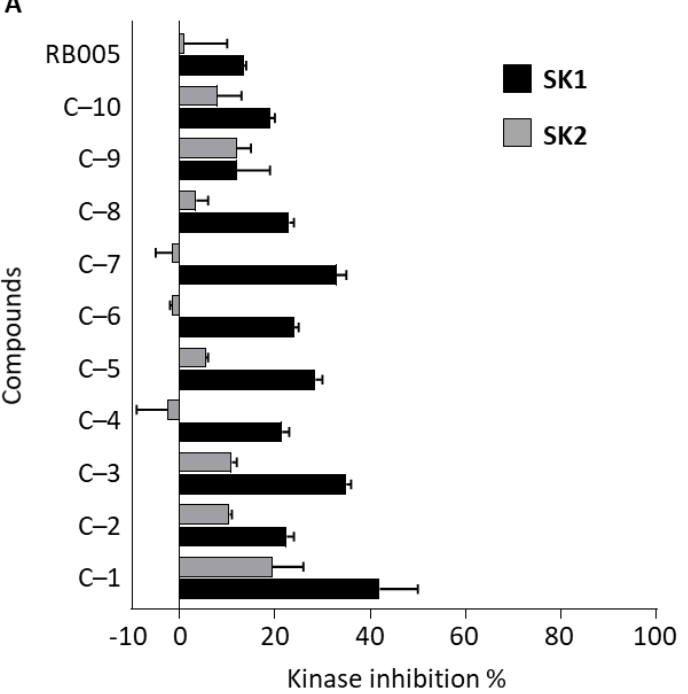

B

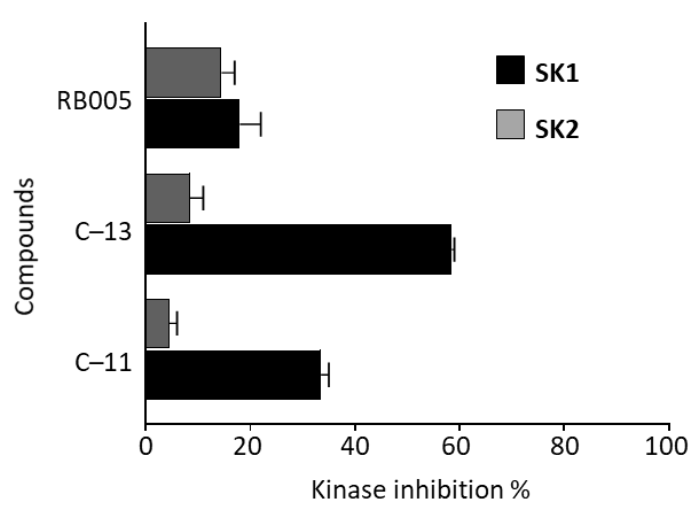

Figure 5. Effects of FTY720 and RB005 derivatives $(20 \mu \mathrm{M})$ on in vitro SK1/2 activity assay. Effect of (A) RB005 and derivatives 1-10 and (B) PF-543 derivatives $\mathbf{1 1}$ and $\mathbf{1 3}$ on SK1/2 activity.

3.2.5. Compound 10 Inhibits Intracellular S1P Production and Increases Proapoptotic Sphingolipids

We observed the protein expression levels of SK1 and 2 to determine whether compound 10 could reduce SK activity by reducing the expression of SK1 and 2. The treatment of 10 and $20 \mu \mathrm{M}$ of compound 10 in HCT116 cells does not affect the SK1 protein expression level compared to control cells, which is similar to the FTY720-treated cells (Figure 6A). Treatment of compound $\mathbf{1 0}$ at 10 and $20 \mu \mathrm{M}$ significantly reduces the S1P levels produced by $\mathrm{SK}$ in a concentration-dependent manner compared to nontreated control cells (Figure 6B). In reverse, $10 \mu \mathrm{M}$ and $20 \mu \mathrm{M}$ of compound $\mathbf{1 0}$ treatment in HCT116 cells increased sphingosine level by 1.42 and 1.74 fold compared to nontreated control cells (Figure 6C). Ceramide level was increased in HCT116 treated with $20 \mu \mathrm{M}$ of compound 10 (Figure 6D). These results indicate that the SK1 protein expression is not affected by the treatment of compound 10. In contrast, the apoptosis in colon cancer cells by compound $\mathbf{1 0}$ could be initiated due to the inhibition of SK1 enzyme activity ensuing a decreased pro-survival S1P lipid mediator level and increased proapoptotic sphingosine and ceramide level within colon cancer cells. 

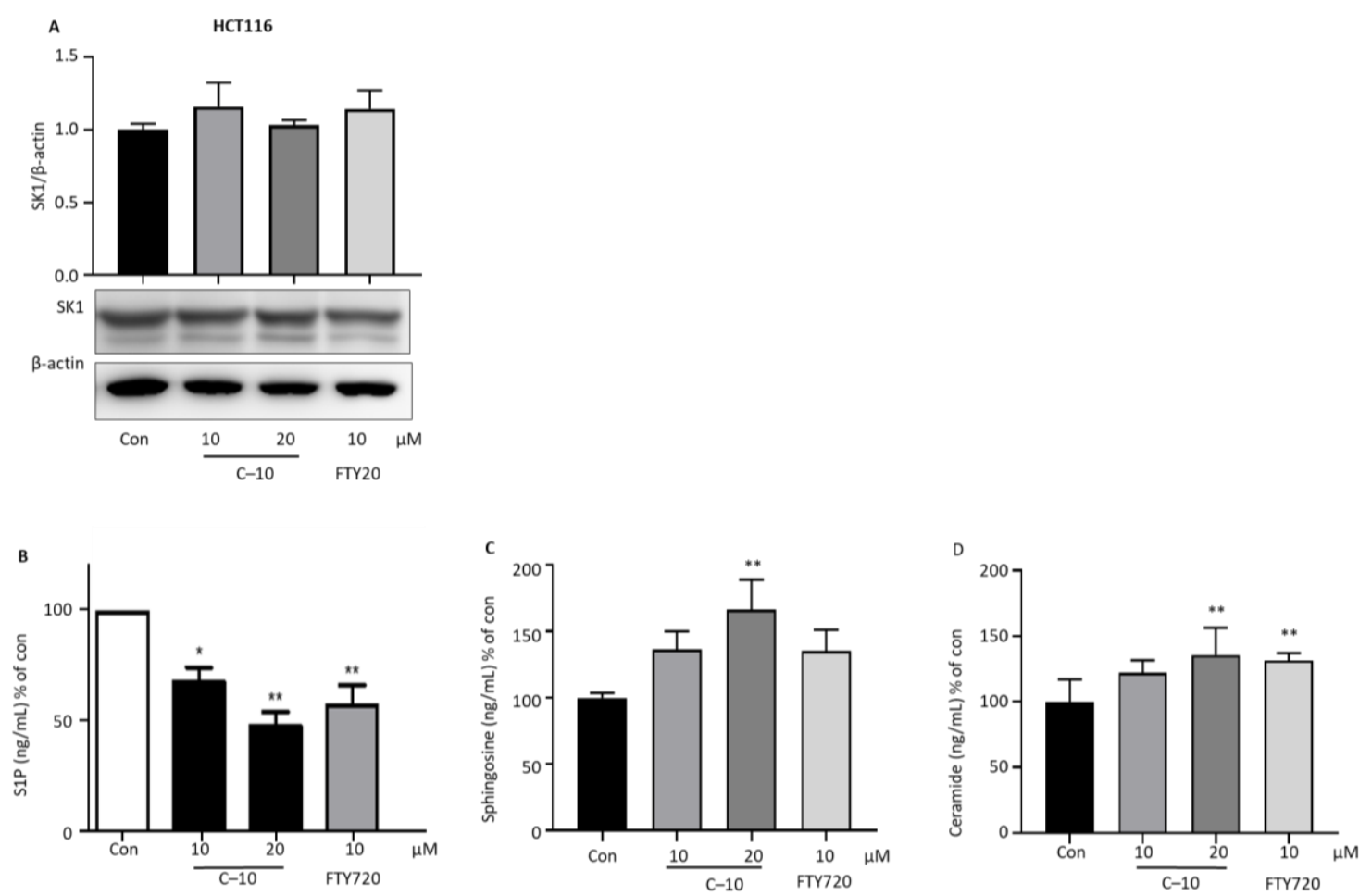

Figure 6. Effect of compound 10 on SK1 expression and sphingolipid-related molecules. HCT116 cells were seeded in 12-well plates and treated with compound $10(10$ and $20 \mu \mathrm{M})$ and FTY720 $(10 \mu \mathrm{M})$ for $24 \mathrm{~h}$. (A) Protein was extracted and performed western blotting of SK1 and quantified as SK1/ $\beta$-actin compared to nontreated control cells. $\beta$-actin was used as the loading control. ELISA was performed for the detection of (B) S1P, (C) sphingosine and (D) ceramide level. The result is representative of three independent experiments, and data are presented as mean $\pm \mathrm{SD} .{ }^{*} p<0.05,{ }^{* *} p<0.01$ compared with nontreated control group.

3.2.6. PP2A Activation Is an Additional Pathway Followed by Compound $\mathbf{1 0}$ for Advanced Anticancer Effect

The cell cytotoxic effects of the novel synthetic compounds 10, 11, 13, and known SK1 inhibitors RB005 and PF-543 were compared at 10, 20 and $40 \mu \mathrm{M}$ concentrations. The cytotoxic effects of compounds $\mathbf{1 0}$ and RB005 with an aliphatic tail structure were higher than compounds 11, 13, and PF-543 with a benzene sulfonyl tail structure in all concentration ranges (Supplementary Figure S1C). Previously, we have shown that RB005 has a higher anticancer effect in colon cancer than PF-543, and PP2A activation was the alternative pathway followed by RB005 but not by PF-543 [13]. Similarly, we conducted a PP2A activity assay of compounds 10, 11 and 13 along with RB005 and FTY720 as a positive control in HCT116 cells. Treatment of compounds $\mathbf{1 1}$ and $\mathbf{1 3}$ did not increase PP2A activity in HCT116 cells, while compound 10 significantly increased PP2A activity by 1.73 fold compared to nontreated control cells (Figure 7A). RB005 and FTY720 increased PP2A activity by 1.59 and 1.65 fold, respectively, compared to control cells. To further validate the activity against PP2A, we observed the phosphorylation levels of AKT (Thr508) and ERK (Thr202), which PP2A dephosphorylates. Treatment of compound 11 and 13 did not decrease phosphorylation of AKT and ERK in HCT116 cells, whereas compound 10 treatments significantly reduced phosphorylation of AKT and ERK, similar to RB005 and FTY720 (Figure 7B,C). In sum, compounds (RB005 and compound 10) containing an aliphatic chain structure show relatively higher PP2A activity than PF-543-type compounds, supporting better anticancer effect of compound $\mathbf{1 0}$ compared with compounds 11 and 13. 
A

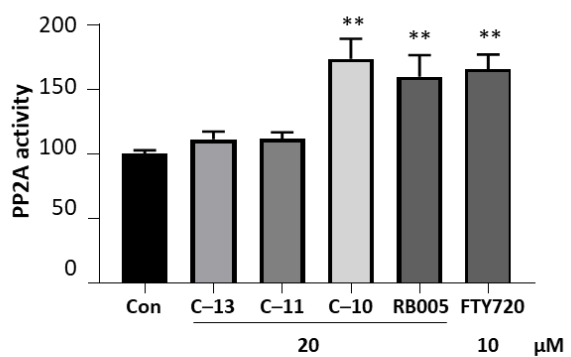

B
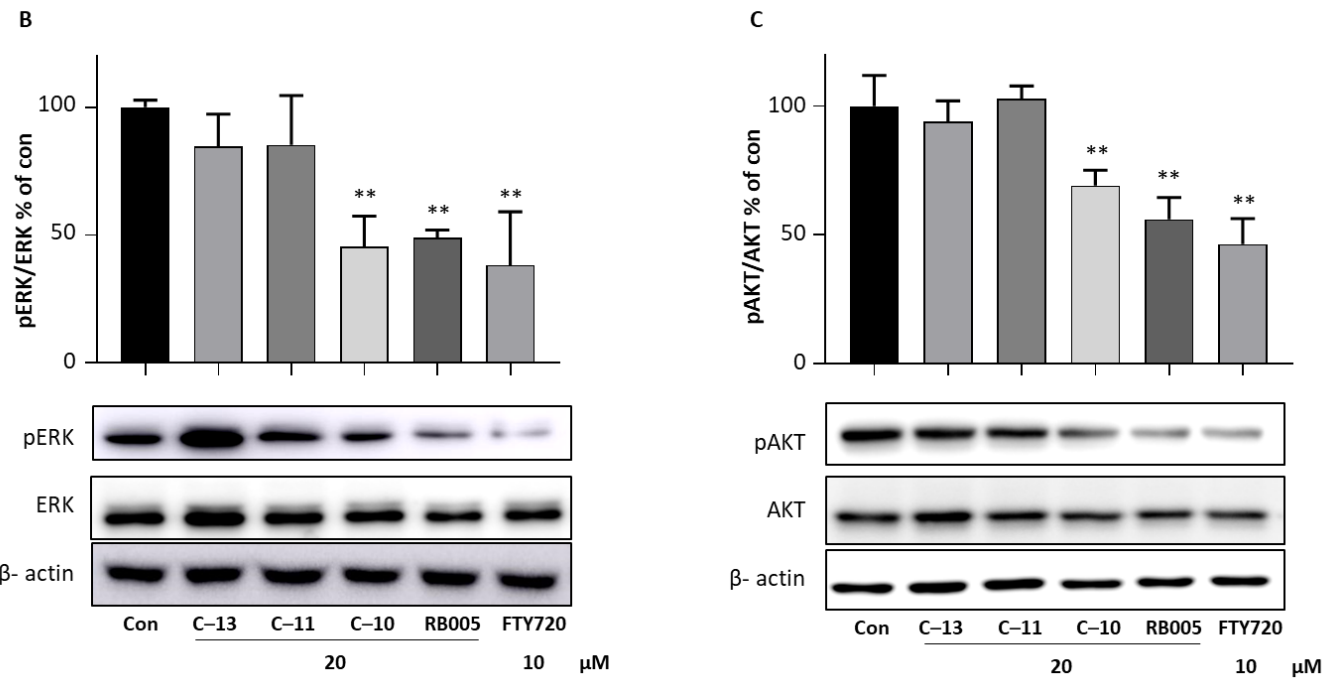

$10 \mu \mathrm{M}$

Figure 7. Effect of compound 10 on PP2A activity. (A) HCT116 cells were seeded in 12-well plates and treated with $20 \mu \mathrm{M}$ of compounds 10, 11, and 13 for $24 \mathrm{~h}$. Cell lysate was performed PP2A activity assay by immunoprecipitation PP2A activity assay kit. HCT116 cells were treated with $20 \mu \mathrm{M}$ of compounds 10, 11, 13, and RB005 and $10 \mu \mathrm{M}$ of FTY720. Expression of (B) ERK and pERK and (C) $\mathrm{AKT}$ and $\mathrm{pAKT}$ was determined and quantified. $\beta$-actin was used as the loading control. The result is representative of three independent experiments, and data are presented as mean \pm SD. ${ }^{* *} p<0.01$ compared with nontreated control group.

3.2.7. Inhibition of CYP Coenzyme Activity and Metabolic Stability by Compound 10, FTY720, and PF-543

The inhibitory ability of each CYP coenzyme activity by compound 10, FTY720, and PF-543 was expressed as percentage activity against the control without the addition of inhibitor. Compound $\mathbf{1 0}$ and FTY720 showed no inhibitory activity against CYP coenzyme or merely weak inhibitory activity. PF-543 exhibits an inhibitory activity of $50 \%$ or more $\left(\mathrm{IC}_{50}<10 \mu \mathrm{M}\right)$ against CYP2C9, 2C19 and 3A4 (Table 3). For the accuracy of our experiment, ketoconazole, a well-known existing CYP3A4 inhibitor, was added as a positive control. As a result, similar research results were obtained.

Table 3. Effect of compound 10, FTY720, and PF-543 in CYP enzyme activity (\% of control activity).

\begin{tabular}{cccccc}
\hline & CYP1A2 & CYP2C9 & CYP2C19 & CYP2D6 & CYP3A4 \\
\hline Compound 10 & $>100$ & $>100$ & 96.5 & 87.4 & $>100$ \\
FTY720 & 86.5 & 96.8 & 86.8 & 92.0 & $>100$ \\
PF543 & 80.9 & 9.3 & 31.0 & 63.9 & 16.8 \\
Ketoconazole & $>100$ & $>100$ & $>100$ & $>100$ & 32.5 \\
\hline
\end{tabular}


The metabolic stability of compound 10, FTY720, and PF-543 was expressed as \% activity against the unreacted control. In vitro profile of FTY720, PF-543, and compound 10 was determined using human (HLM), rat (RLM) and mouse (MLM) liver microsomal stability (\% remaining after $30 \mathrm{~min}$ ). Compound 10 was stable in human species but unstable in rats and mice liver microsomal stability. FTY720, which is already used as a drug, was observed to be stable in the three evaluated species. The liver microsomal stability of PF-543was unstable in all species (Table 4).

Table 4. In vitro stability study of compound 10, FTY720, and PF-543 compared with verapamil on human, rat, and mouse liver microsomes.

\begin{tabular}{cccc}
\hline Compound & Human (\%) & Rat (\%) & Mouse (\%) \\
\hline Compound 10 & 70.3 & 10.2 & 44.7 \\
FTY720 & 90.5 & 77.0 & 89.9 \\
PF543 & 13.5 & 8.1 & 6.5 \\
Verapamil (Reference) & 14.4 & - & - \\
\hline
\end{tabular}

\section{Discussion}

In this study, RB005 derivatives (compounds 1-10) and PF-543 derivatives (compounds 11-20), well-known as SK1 inhibitors, were synthesized using the same starting material, and the efficacy of these compounds on the cell cytotoxic effect of colorectal cancer cells was verified. Among 1-10, compound 10 showed the best cytotoxic effect in HT29 and HCT116 cells after $24 \mathrm{~h}$ and $48 \mathrm{~h}$. To endorse whether cytotoxicity exhibited by compound 10 was due to apoptosis, annexin V-FITC assay and apoptotic signaling molecule expression were determined. Compound $\mathbf{1 0}$ is a derivative of RB005, but RB005 is also an analog of FTY720, and FTY720 is superior to RB005 in cytotoxic effect, so the efficacy of apoptosis was verified compared with FTY720. It showed a similar apoptotic effect with FTY720, and an increase in the proapoptotic protein BAX and PARP cleavage by caspase- 3 was also observed. Using the same starting material as the synthesis method for compounds 1-10, analogs 11-20 with benzenesulfonyl tail similar to PF-543 were synthesized. Most of the PF-543 analogs showed lower anticancer activity than FTY720 or RB005, which have aliphatic chains, and lower cell cytotoxic effect than 5-Fluorouracil. As a result of the apoptosis efficacy, it was found that the cytotoxic effects of compounds having an aliphatic tail, such as FTY720 and RB005, were better. Therefore, to increase the apoptosis efficacy, maintaining the aliphatic structure can be expected to have an improvement effect through a synthetic approach. We conducted the SK1/2 inhibitory effect of the first set of synthesized compounds together with the known SK1 inhibitor RB005. Most of the RB005 derivatives showed improved SK1 inhibitory ability than RB005. However, it was found that the SK1 inhibitory ability and the cytotoxic effect were not directly proportional. SK inhibitors inhibit the transformation of sphingosine into S1P in cancer cells and show anticancer activity, as S1P is a well-known lipid modulator involved in cancer cell survival and proliferation [14]. Since compound 10 has an SK inhibitory effect, it can be observed that the level of S1P is decreased and that the level of sphingosine and ceramide, which are apoptosis factors, is increased. PF-543 analogs had a more SK1 selectivity and SK1 inhibitory effect than RB005. In particular, compared with compound 10, it can be seen that compounds $\mathbf{1 1}$ and 13, which are two types of PF-543 analogs, improved the inhibitory effect and selectivity of SK1. However, in terms of cytotoxicity and apoptosis, it was found that compound $\mathbf{1 0}$ was superior to the PF-543 analogs. These results are consistent with a previous report [14] of low anticancer activity compared to the excellent SK1 inhibitory effect of PF-543. As a result, it can be suggested that the introduction of the benzenesulfonyl tail is helpful for SK1 selectivity and activity, but the introduction of the aliphatic tail structure is more important to improve the in vitro apoptosis efficacy.

Previously, we have developed numerous SK inhibitors and tested them in various cancer cells [7,15-18]. These experiences provide us with much information about the role of sphingosine kinase inhibitor's structure and its anticancer properties. PF-543 is a 
selective and most potent SK1 inhibitor; however, its anticancer response was lower than that of FTY720 and RB005, which are less potent SK1 inhibitors. Our results revealed that compound $\mathbf{1 0}$ had a stronger cytotoxic effect than SK1 inhibitory ability. The discrepancy between these results suggests that a mechanism other than SK inhibitory efficacy is involved in the cancer cell cytotoxic efficacy of SK inhibitors. In a previous study, we showed that PP2A activation of FTY720 and RB005 is an additional compensatory mechanism for their superior anticancer properties in colorectal cancer [13].

PP2A acts as a tumor suppressor by regulating many signaling pathways, and a decrease in PP2A function affects cancer cell transformation [19]. The correlation between the activity of PP2A and cancer has been reported in several cancers [20]. There is some evidence suggesting a relevant role of the PP2A deregulation in colorectal cancer pathogenesis, and the increase in PP2A activity by FTY720 inhibits cell growth in colorectal cancer cells. Therefore, activation of PP2A can be a drug target for colorectal cancer treatment. An experiment was conducted to confirm whether compound 10, an analog of RB005 and FTY720, and compound 11, with a tail structure of PF-543, activate PP2A like FTY720 to show anticancer activity. As a result, it was found that PP2A was activated in compound $\mathbf{1 0}$ treated with HCT116 cell lines. Because of treatment with compound $\mathbf{1 0}$ in the HCT116 cell line, PP2A activity was observed similar to RB005 and FTY720. Activation of PP2A by compound 10 increases the dephosphorylation of ERK and AKT, which are factors that promote cancer cell growth, thereby inducing apoptosis and contributing to inhibit cell growth. The results of PP2A activation explain the enhancement of anticancer activity in colorectal cancer of synthetic compounds. Therefore, the activity of PP2A may be more effective in anticancer activity than the inhibition of SK1. In addition, it is possible that the aliphatic chain of the FTY720 form is structurally effective in obtaining the result of PP2A activation. To reliably prove these results, more results on the synthesis of derivatives are needed.

For a compound to be developed as a drug, improving pharmacokinetics is one of the important issues. The enzymatic protein superfamily cytochrome P450 (CYP) are involved in the metabolism of drugs accompanying variability of drug pharmacokinetics and response. The major forms of CYP enzyme expressed in the liver are CYP1A2, CYP2C9, CYP2C19, CYP2D6 and CYP3A4; they are involved in drug metabolism and determine the fate of the drug adverse reactions or therapeutic failure [21,22]. Since compound 10 did not affect the activity of major CYP enzymes, consequently, it is judged that there is slight possibility of drug interaction with drugs metabolized by these coenzymes. In general, the percentage of control activity or $\mathrm{IC}_{50}$ value is affected by the concentration of the substrate drug. To predict in vitro to in vivo interactions, an additional study obtaining the Ki (inhibition constant) value (full enzyme inhibition study) may be needed. In addition, to predict the possibility of drug interaction more accurately, it is more important to know the concentration of test compounds in plasma and in the liver tissue, so further studies are considered necessary.

Metabolic stability is a factor that can affect PK parameters, such as drug clearance, half-life, and oral bioavailability, and is considered an important characteristic of drug candidates for defining pharmacological and toxicological profiles as well as patient compliance of a drug [23]. This experiment predicted the degree of drug metabolism by the liver, a major organ involved in drug metabolism, through an in vitro experiment. Metabolically active systems, such as liver microsomes or hepatocytes, are used to evaluate the metabolic stability of drugs. To avoid the problem of metabolic potential, a compound with a value of at least $60 \%$ for $30 \mathrm{~min}$ is ideal. Still, liver microsomal stability may vary depending on the conditions of each compound. Compound $\mathbf{1 0}$ showed CYP enzymatic activity similar to that shown by FTY720, which has already been developed as a drug, and showed excellent microsomal stability in human (HLM) compared with the known SK1 inhibitor PF-543. These results suggest that the tail structure having a heteroatom is a relatively stable drug, but in vivo PK studies are needed to reflect PK information for drug designing and synthesis. 


\section{Conclusions}

The newly synthesized compounds $\mathbf{1 - 1 0}$ showed an overall increase in SK1/2 inhibitory effect compared to RB005 in the aliphatic tail, and, in particular, compound 3 in the head group such as RB005 showed three times higher SK1/2 inhibitory effect than RB005. These results show that the compounds of the tail structure connected by the heteroatom influence the increase of the SK1/2 inhibitory effect as well as the synthetic convenience. In addition, there was no difference in the SK1/2 inhibitory effect according to the head group, which shows that the change in the tail group is more effective in the SK1/2 inhibitory effect.

Compound 11 with a tail and head structure like PF-543 demonstrated higher SK1 selectivity than SK2 but showed low anticancer activity results. On the other hand, compound 10 with an aliphatic chain showed relatively high PP2A activity. This shows that the introduction of aliphatic chains is structurally effective in developing anticancer drugs using SK1 inhibitors.

In this study, we showed that compound 10, a novel SK1 inhibitor with aliphatic chains linked by a heteroatom, improved anticancer activity compared to RB005. In addition, compound 10 showed metabolic stability similar to that of FTY720 in liver microsomes of humans and low inhibitory ability to CYP enzymes. These results could be used as important information for designing new anticancer active substances using SK1 inhibitory effect and PP2A activation.

Supplementary Materials: The following are available online at https:/ /www.mdpi.com/article/10 .3390 / pharmaceutics14010157/s1. Figure S1: Relative $\mathrm{IC}_{50}$ determination of compound 10 (A, B), and comparison of cytotoxicity of compound 10 with compound 11 and 13 (C). Figure S2: The effects of compounds in the viability of pancreatic cancer and gastric cancer cells.

Author Contributions: T.L. and D.J.B. designed the compounds; S.-B.K. (Sang-Bum Kim) and T.P. measured the metabolic stability; D.J.B. synthesized compounds; J.S., S.W.K., S.-B.K. (Su-Bin Kim), Y.S.O. and E.-Y.P. conducted the biological studies; J.S., S.H.K., D.J.B. and E.-Y.P. wrote this paper. All authors have read and agreed to the published version of the manuscript.

Funding: This research was supported by the Basic Science Research Program through the National Research Foundation of Korea (NRF) funded by the Ministry of Science, ICT \& Future Planning (2020R1A2C1012156 and 2020R1F1A1068316). This work was carried out by the Convergence Research Laboratory established by the Mokpo National University (MNU) Innovation Support Project.

Conflicts of Interest: All authors declare no financial/commercial conflict of interest.

\section{References}

1. Kohama, T.; Olivera, A.; Edsall, L.; Nagiec, M.M.; Dickson, R.; Spiegel, S. Molecular cloning and functional characterization of murine sphingosine kinase. J. Bio. Chem. 1998, 273, 23722-23728. [CrossRef]

2. Wang, P.; Yuan, Y.; Lin, W.; Zhong, H.; Xu, K.; Qi, X. Roles of sphingosine-1-phosphate signaling in cancer. Cancer Cell Int. 2019, 19, 295. [CrossRef]

3. Neubauer, H.A.; Pham, D.H.; Zebol, J.R.; Moretti, P.A.; Peterson, A.L.; Leclercq, T.M.; Chan, H.; Powell, J.A.; Pitman, M.R.; Samuel, M.S.; et al. An oncogenic role for sphingosine kinase 2. Oncotarget 2016, 7, 64886-64899. [CrossRef]

4. Wang, X.; Sun, Y.; Peng, X.; Naqvi, S.M.A.S.; Yang, Y.; Zhang, J.; Chen, M.; Chen, Y.; Chen, H.; Yan, H.; et al. The Tumorigenic Effect of Sphingosine Kinase 1 and Its Potential Therapeutic Target. Cancer Control 2020, 27, 1073274820976664. [CrossRef]

5. French, K.J.; Schrecengost, R.S.; Lee, B.D.; Zhuang, Y.; Smith, S.N.; Eberly, J.L.; Yun, J.K.; Smith, C.D. Discovery and evaluation of inhibitors of human sphingosine kinase. Cancer Res. 2003, 63, 5962-5969. [PubMed]

6. Guan, H.; Liu, L.; Cai, J.; Liu, J.; Ye, C.; Li, M.; Li, Y. Sphingosine kinase 1 is overexpressed and promotes proliferation in human thyroid cancer. Mol. Endocrinol. 2011, 25, 1858-1866. [CrossRef]

7. Shrestha, J.; Ki, S.H.; Shin, S.M.; Kim, S.W.; Lee, J.-Y.; Jun, H.-S.; Lee, T.; Kim, S.; Baek, D.J.; Park, E.-Y. Synthesis of novel FTY720 analogs with anticancer activity through PP2A activation. Molecules 2018, 23, 2750. [CrossRef] [PubMed]

8. Britten, C.D.; Garrett-Mayer, E.; Chin, S.H.; Shirai, K.; Ogretmen, B.; Bentz, T.A.; Brisendine, A.; Anderton, K.; Cusack, S.L.; Maines, L.W. A phase I study of ABC294640, a first-in-class sphingosine kinase-2 inhibitor, in patients with advanced solid tumors. Clin. Cancer Res. 2017, 23, 4642-4650. [CrossRef] [PubMed] 
9. Schnute, M.E.; McReynolds, M.D.; Kasten, T.; Yates, M.; Jerome, G.; Rains, J.W.; Hall, T.; Chrencik, J.; Kraus, M.; Cronin, C.N.; et al. Modulation of cellular S1P levels with a novel, potent and specific inhibitor of sphingosine kinase-1. Biochem. J. 2012, 444, 79-88. [CrossRef]

10. Pitman, M.R.; Costabile, M.; Pitson, S.M. Recent advances in the development of sphingosine kinase inhibitors. Cell. Signal. 2016, 28, 1349-1363. [CrossRef]

11. Schnute, M.E.; McReynolds, M.D.; Carroll, J.; Chrencik, J.; Highkin, M.K.; Iyanar, K.; Jerome, G.; Rains, J.W.; Saabye, M.; Scholten, J.A.; et al. Discovery of a potent and selective sphingosine kinase 1 inhibitor through the molecular combination of chemotype-distinct screening hits. J. Med. Chem. 2017, 60, 2562-2572. [CrossRef]

12. Kim, S.W.; Lee, T.; Oh, Y.S.; Shin, S.M.; Lee, J.-Y.; Kim, S.; Baek, D.J.; Park, E.-Y. Synthesis and biological evaluation of PF-543 derivative containing aliphatic side chain. Chem. Pharm. Bull. 2019, 67, 599-603. [CrossRef] [PubMed]

13. Shrestha, J.; Shamshiddinova, M.; Lee, Y.-M.; Oh, Y.S.; Baek, D.J.; Park, E.-Y. SK1 inhibitor RB005 Induces Apoptosis in Colorectal Cancer Cells through SK1 Inhibition Dependent and Independent Pathway. Curr. Mol. Pharmacol. 2021, 14, 1. [CrossRef]

14. Grbčić, P.; Sedić, M. Sphingosine 1-phosphate signaling and metabolism in chemoprevention and chemoresistance in colon cancer. Molecules 2020, 25, 2436. [CrossRef]

15. Baek, D.J.; MacRitchie, N.; Pyne, N.J.; Pyne, S.; Bittman, R. Synthesis of selective inhibitors of sphingosine kinase 1. Chem. Commun. 2013, 49, 2136-2138. [CrossRef] [PubMed]

16. Shrestha, J.; Hwang, G.T.; Lee, T.; Kim, S.W.; Oh, Y.S.; Kwon, Y.; Hong, S.W.; Kim, S.; Moon, H.S.; Baek, D.J.; et al. Synthesis and Biological Evaluation of BODIPY-PF-543. Molecules 2019, 24, 4408. [CrossRef]

17. Shrestha, J.; Lee, J.-Y.; Park, E.-Y.; Baek, D.J. Synthesis of PF-543 Derivatives Using Simple Synthetic Methods and Their Biological Effect Analysis for the Development of Anticolorectal Cancer Agents. Lett. Drug Des. Discov. 2021, 18, 85-92. [CrossRef]

18. Park, E.-Y.; Lee, T.; Oh, Y.S.; Lee, J.-Y.; Shrestha, J.; Hong, S.W.; Jin, Y.J.; Jo, G.; Kim, S.; Hwang, G.T.; et al. Synthesis of dansyl labeled sphingosine kinase 1 inhibitor. Chem. Phys. Lipids 2018, 215, 29-33. [CrossRef] [PubMed]

19. Cristóbal, I.; Manso, R.; Rincón, R.; Caramés, C.; Senin, C.; Borrero, A.; Martínez-Useros, J.; Rodriguez, M.; Zazo, S.; Aguilera, O.; et al. PP2A inhibition is a common event in colorectal cancer and its restoration using FTY720 shows promising therapeutic potential. Mol. Cancer Ther. 2014, 13, 938-947. [CrossRef]

20. Zhang, L.; Wang, H.-D.; Ji, X.-J.; Cong, Z.-X.; Zhu, J.-H.; Zhou, Y. FTY720 for cancer therapy. Oncol. Rep. 2013, 30, 2571-2578. [CrossRef]

21. Lynch, T.; Price, A.L. The effect of cytochrome P450 metabolism on drug response, interactions, and adverse effects. Am. Fam. Physician 2007, 76, 391-396. [PubMed]

22. Zanger, U.M.; Schwab, M. Cytochrome P450 enzymes in drug metabolism: Regulation of gene expression, enzyme activities, and impact of genetic variation. Pharmacol. Ther. 2013, 138, 103-141. [CrossRef] [PubMed]

23. Masimirembwa, C.M.; Bredberg, U.; Andersson, T.B. Metabolic stability for drug discovery and development. Clin. Pharmacokinet. 2003, 42, 515-528. [CrossRef] [PubMed] 